\title{
EREBEA
}

Revista de Humanidades y Ciencias Sociales

Núm. 9 (2019), pp. 189-222

ISSN: 0214-0691

http://dx.doi.org/10.33776/erebea.v9i0.3790

\section{LOS MUSEOS DE ARTE CONTEMPORÁNEO EN EL PAISAJE URBANO DE LA CIUDAD DE CUENCA}

\author{
Ana Eulalia Aparicio Guerrero \\ Universidad de Castilla-La Mancha
}

Cayetano Espejo Marín

Universidad de Murcia

RESUMEN

El artículo se estructura en dos partes bien diferenciadas. En una primera se aborda el análisis del paisaje urbano, la evolución geológica, histórica y urbana de la ciudad antigua, así como las características tipológicas de sus edificaciones y distintas perspectivas del Casco Histórico. Y en una segunda parte se presentan tres edificios históricos infrautilizados que fueron objeto de una rehabilitación con cambio de uso para instalar en ellos diversas colecciones de arte contemporáneo: Museo de Arte Abstracto Español, Fundación Antonio Pérez y Espacio Torner, edificios que se han convertido en hitos del paisaje urbano y en iconos culturales al ser puntos de referencia para los flujos turísticos de los viajeros que visitan Cuenca.

Palabras Clave

Paisaje, naturaleza, cultura, museos, colección, arte, Cuenca, España

Fecha de recepción: 10 de noviembre de 2019 Fecha de aceptación: 5 de diciembre de 2019

\section{ABstract}

The article is structured in two well differentiated parts. The first part deals with the analysis of the urban landscape, the geological, historical and urban evolution of the old city, as well as the typological characteristics of its buildings and different perspectives of the historic center. The second part presents three underutilized historical buildings that underwent a rehabilitation to change their use to install various collections of contemporary art in them: Museum of Spanish Abstract Art, the Antonio Pérez Foundation and the Torner Space. These buildings have become landmarks of the urban landscape and cultural icons as points of reference for tourist flows of travelers visiting Cuenca.

\section{KeYwords}

Landscape, nature, culture, museums, collection, art, Cuenca, Spain 



\section{i. Introducción. Museos y paisaje urbano. El caso de Cuenca}

Las interacciones más singulares entre la sociedad y el medio natural han sido reconocidas por la UNESCO con el término "paisaje cultural". Se trata de un tipo particular de patrimonio cultural con el que se valora la expresión morfológica, funcional, percibida y simbólica de territorios únicos que han sido construidos por el ser humano a lo largo de la historia; generaciones que interactuaron en el medio natural y en un territorio concreto en una realidad dinámica y compleja (Escudero y De la O, 2016). Tal es la importancia que se les otorga, que desde la UNESCO hasta los Estados nacionales desarrollan planes para su reconocimiento y protección. Un paisaje cultural que en la ciudad de Cuenca encontramos asociado a dos elementos esenciales, uno natural: dos ríos y las hoces excavadas por ellos en la caliza, y otro histórico: el Medievo (Frías, 2016). El asentamiento urbano fundado por los musulmanes entre las hoces de los ríos Júcar y Huécar, origen de la actual ciudad de Cuenca, ha dado lugar al paisaje de su Casco Histórico y de las cornisas labradas por ambos ríos.

"Paisaje" no es naturaleza, no es territorio, no es ambiente... y claramente, siempre es cultural. Las definiciones de "paisaje cultural" enfatizan que se trata de una combinación de naturaleza e historia (UNESCO, 1972; ICOM, 2016), no hay paisaje que no sea cultural, puesto que es la mirada social humana la que le da entidad al entorno, la que "lee" el mundo de una cierta forma y no de otra, dependiendo de la sociedad de que se trate. Los paisajes culturales definidos como tales por la UNESCO se caracterizan por su gran impacto visual, o estético, y por la antropización, por los efectos claramente visibles de la acción humana sobre el ambiente (Nazor, 2016). La identidad colectiva, lo identitario, está en relación con el paisaje cultural. El paisaje muestra la identidad, el carácter y la esencia de un territorio. De él depende nuestra proyección exterior y en parte nuestra economía. La experiencia turística encuentra todo su sentido en el marco de un paisaje porque constituye un recurso y un atractivo por su diversidad, rasgos peculiares y sus valores. Es el resultado del trabajo combinado de la naturaleza y el ser humano (Alba, Cortijo e Iranzo, 2017).

La relación de las ciudades históricas con el medio natural circundante ha sido un elemento básico en el diseño y redacción de los planes especiales de los centros históricos españoles. En Cuenca, la consideración del paisaje de su casco antiguo como la suma del medio natural de las hoces y la arquitectura del recinto 
urbano tiene como fin la protección del entorno natural como elemento esencial del paisaje cultural del conjunto histórico (Aparicio, 2013).

Además, el modelo económico existente en España ha convertido la cultura en una vertiente de la economía, percibiéndose las actividades artísticas como un capítulo específico dentro de los ingresos turísticos. La relación entre los paisajes culturales y los museos fue el eje temático de la $24^{\circ}$ Conferencia General del International Council of Museums (ICOM), celebrada el 18 de mayo de 2016, Día Internacional de los Museos. Según ICOM (2007), "El museo es una institución permanente, sin fines de lucro, al servicio de la sociedad y abierta al público, que adquiere, conserva, estudia, expone y difunde el patrimonio material e inmaterial de la humanidad con fines de estudio, educación y recreo". Los museos se han convertido en iconos al ser un punto de referencia para los flujos turísticos y cosmopolitas de los viajeros en la sociedad del ocio (Eco y Pezzini, 2014). Según Santiago Langreo (2018), si los museos representaron el poder, luego el conocimiento, y más tarde la identidad cultural de una comunidad, hoy deben representar la capacidad de construir futuro.

En una época en la que la tecnología ha hecho posible la visión de una obra de arte por millones de personas al mismo tiempo, el museo sigue garantizando a un número reducido de personas la experiencia directa e irresistible de su contemplación y de su goce estético. Quizás sea ésta la mejor y única garantía para su supervivencia a pesar de los violentos cambios que cada día nos impone una sociedad tecnológica en la que los valores cuantitativos parecen querer superar a los cualitativos (Jiménez Blanco, 1993).

España es un país de referencia en cuanto a la fundación de nuevos museos como emblema político de un proceso de descentralización en la política cultural (Bolaños, 2008). La etapa de prosperidad económica de las últimas décadas y el desarrollo territorial de las Comunidades Autónomas ha dado lugar a la creación de gran cantidad de museos y centros de arte contemporáneo, sin ningún patrón común en sus planteamientos ni en cuestiones arquitectónicas o urbanísticas, aunque casi siempre se ha pretendido que tuvieran un efecto dinamizador del entorno, aparte de que unas veces se hayan habilitado edificios antiguos, otras se hayan construido nuevos con esa función $y$, a menudo, se hayan combinado ambas opciones (Lorente, 2008).

Hay que destacar el papel del museo como institución cultural y como elemento definidor del paisaje urbano, al constituir una pieza clave en la definición de ciertas áreas de la ciudad. Los museos se convierten en polos urbanos que caracterizan a las ciudades que los poseen y constituyen una de las ofertas culturales más atractivas para el turista que visita la ciudad. Los museos han sido considerados tradicionalmente los referentes culturales por excelencia. Actualmente resalta su papel como regenerador urbano, por ser pieza clave de planes y proyectos de rehabilitación y recuperación en el marco de las políticas 
urbanísticas de ciudades españolas y europeas (Vacas, 2014). Como afirma Diego Barrado (2012), a la función cultural inherente a un proyecto museístico se le han de sumar la económica ligada al turismo y a la revitalización del conjunto de la ciudad, la urbanística, dirigida a la regeneración de áreas centrales más o menos degradadas, y la política, como legitimación del poder a través de símbolos claramente visibles. No obstante, si se asume la función económica ha de aceptarse que la revitalización, la atracción de capitales o de turistas no se produce a partir de la existencia de un recurso, sino por la conversión de este en un producto atractivo y su comercialización y comunicación a través de estrategias adecuadas.

Un caso destacado como iniciativa pionera de base, liderada por un grupo de artistas e intelectuales que dieron ejemplo temprano de preocupación por la revitalización del tejido urbano de poblaciones históricas, la constituye el Museo de Arte Abstracto Español, instalado por Zóbel y Torner en las Casas Colgadas de Cuenca en 1966 (Lorente, 1998).

Dos hechos han sido fundamentales en la creación de los tres museos de arte contemporáneo en Cuenca. Por un lado, la voluntad por parte de los propietarios de las colecciones para donar sus obras sin ningún tipo de contraprestación; y por otro lado, la disponibilidad de los espacios adecuados para convertirlos en museos y el interés de las Administraciones para su cesión: Ayuntamiento de Cuenca (Museo de Arte Abstracto Español), Diputación Provincial de Cuenca (Fundación Antonio Pérez) y Ministerio de Cultura del Gobierno de España (Espacio Torner). Los tres se han instalado en conventos -Fundación Antonio Pérez y Espacio Torner- o en edificios históricos reutilizados -Museo de Arte Abstracto Espańol- en la hoz del Huécar.

La creación del Museo de Arte Abstracto Español era algo insólito en el panorama espańol del momento por muchas razones. En primer lugar, porque respondía a la iniciativa de un coleccionista, contribuyendo a la progresiva visibilidad de esta figura en el terreno cultural y social del país; en segundo lugar, por cumplir un plan para "el cabal entendimiento de la historia que se trataba de reconstruir"; y, en tercer lugar, por el objeto al que se refiere el plan; en 1966 "no existía ningún lugar donde ver en condiciones la obra de los abstractos. Algunos estaban representados en las colecciones del Estado, pero no en la medida de su importancia, y no siempre con sus obras más significativas" (Bonet, 1991).

El análisis de las trayectorias vitales de Zóbel, Torner y Antonio Pérez pone de manifiesto el papel que los coleccionistas han tenido y siguen teniendo en el desarrollo del patrimonio artístico de nuestro país. La vocación pública de un coleccionista es el deseo de participar en la difusión de la cultura, poniendo a disposición las obras que posee (Bolaños, M., 2011). La existencia de estos museos de arte contemporáneo de referencia nacional e internacional ha contribuido a que en los últimos años Cuenca haya sido distinguida como sede de importantes 
muestras expositivas de imprescindibles artistas contemporáneos como Ai Weiwei o Bill Viola (Martínez, 2018).

El objetivo del artículo se centra en presentar los museos de arte contemporáneo como parte integrante de la cultura y del paisaje cultural del Casco Histórico de Cuenca, constituyéndose en recursos turísticos por los contenidos y por los continentes que los albergan, piezas clave de su arquitectura histórica y, en el caso del Museo de Arte Abstracto Español, imagen de la ciudad durante décadas. Para ello nos vamos a centrar en las tipologías arquitectónicas existentes en este espacio urbano, pero sobre todo en las características edificatorias de la cornisa del río Huécar que aglutina tres de los museos de arte contemporáneo de la ciudad con más proyección exterior.

El artículo se estructura, aparte de la presentación, conclusiones y bibliografía, en dos partes bien diferenciadas. En la primera se aborda el análisis del paisaje urbano como tal, su origen, la evolución geológica, histórica y urbana de la ciudad antigua, así como las características tipológicas de sus edificaciones; y en la segunda parte, se presentan los tres edificios históricos que han sido objeto de una rehabilitación con cambio de uso para instalar en ellos tres importantes colecciones de arte contemporáneo.

\section{BREVES APUNTES SObRE LA EVOlUCiÓN GEOLÓGICA, históRICA Y URBANA DE LA} CiUdAd ANTIGUa DE CUenca

La ciudad de Cuenca, puerta de la comarca de la Serranía, se encuentra ubicada en una zona montañosa perteneciente al Sistema Ibérico. Sus materiales secundarios fueron plegados y fallados durante el movimiento alpino. Posteriormente, los fenómenos erosivos nivelaron los relieves de este sector de la Serranía. En el Cuaternario los ríos se encajaron mediante erosión lineal a partir de la superficie de erosión, cortando el relieve y originando cañones kársticos con paredes de piedra prácticamente verticales en las que quedaron en resalte, en las partes altas, las dolomías masivas del Turonense (García Marchante y Fernández, 1999: 6).

Los musulmanes, en el siglo IX, aprovecharon estas características topográficas para fundar una ciudad fortaleza en el escarpe existente entre las hoces: las formadas por los ríos Huécar y Júcar, en el anticlinal calcáreo de Bascuñana, uno de los mejores emplazamientos defensivos de la Serranía, para controlar el paso de la Meseta al Valle del Ebro. A partir del Castillo, en la parte más alta, el espacio urbano se fue extendiendo a menor altitud entre las vertientes de los citados ríos.

Con la conquista de Alfonso VIII en 1177 pasa a manos cristianas y se inicia la edificación de la ciudad cristiana con un marco legal, el Fuero. La conquista de la ciudad supone el inicio del poder religioso al ser sede episcopal, y la configuración de la ciudad como uno de los baluartes de la Reconquista tras la instalación de 
la orden militar de Santiago. Catedral, parroquias, conventos, hospitales, etc., se convirtieron en elementos singulares del paisaje urbano. Desde entonces se produce un impulso demográfico como consecuencia de la repoblación y se afianza su base económica, la textil, resultado de la fusión de las técnicas musulmana y cristiana. La ciudad crece en altura (el Fuero de Cuenca explicita: "cualquiera que construye una casa, levante la altura que le plazca") e inicia el desarrollo hacia las zonas más bajas (Troitińo, 1998a: 61-62).

En la Baja Edad Media se consolida la industria lanera y se produce la expansión demográfica. A mediados del siglo XV se rebasa el recinto amurallado, que coincide aproximadamente con el curso del Huécar, en contacto ya con el valle (Troitiño, 1984: 26 y Fernández, 1995: 366). En la primera mitad del siglo XVI la ciudad se consolida como centro fabril (Troitińo, 1998b: 126). Es entonces cuando surgen los nuevos barrios extramuros, la burguesía se establece en Carretería, donde se inicia el plano que daría lugar al ensanche de la ciudad en el XIX, y los trabajadores en San Antón y Tiradores. En la segunda mitad del siglo XVI se produce la crisis de la industria textil, el hundimiento de la burguesía y la pobreza de las clases populares.

Esta situación lleva al control de la sociedad por parte de la Iglesia en el XVII. En el siglo XVIII la Iglesia y la Nobleza se disputarán el poder y el control del espacio. En el siglo XIX la Guerra de la Independencia termina con la industria textil, desapareciendo los pequeños telares artesanales. La crisis económica incide en el descenso de la población. El plano apenas registra transformaciones, pero se producen graves deterioros en el paisaje urbano: hundimientos de algunas iglesias y la torre del Giraldillo de la Catedral, y derribos de las puertas de la muralla y del puente de San Pablo. Este último, construido en el siglo XVI para unir la ciudad con el convento de San Pablo, había iniciado su deterioro en 1776. En 1886 se derriba con intención de levantar uno de hierro. En 1902, con la construcción de la pasarela de Fuster, Cuenca se incorpora a "la arquitectura del hierro". La ciudad alta continúa teniendo un importante peso residencial, pero pierde equipamiento administrativo y comercial con el paso de los años.

\section{Paisaje natural y paisaje de cultura. La ciudad paisaje}

Las intervenciones del hombre durante el paso de los siglos han transformado el paisaje natural en paisaje de cultura. La peculiaridad de esta ciudad se debe a que sus recursos culturales y naturales se encuentran conectados intrínsecamente, haciendo que su patrimonio monumental y natural se fusionen, generando un atractivo paisaje para el visitante (Vacas y De la Fuente, 2016). El paisaje cultural, al conservar las huellas y herencias de nuestra civilización, constituye un patrimonio cultural de valor incalculable que, junto al urbanismo, hacen de la ciudad antigua el símbolo de la personalidad urbana de Cuenca, su imagen de marca (Troitiño, 1998b). Según Manuel Valenzuela, el Casco Antiguo de Cuenca 
acapara la mayor parte de los valores culturales, históricos, arquitectónicos y urbanísticos que simbolizan a la ciudad y le dan personalidad propia entre los paisajes urbanos de las ciudades españolas y mundiales (Valenzuela, 1988).

"Cuenca es uno de los más claros ejemplos que se pueden encontrar de vinculación de una ciudad con su entorno natural. La tendencia creciente a disociar los ámbitos urbanos de los que pertenecen a espacios abiertos encuentra en este caso un paradigma de lo contrario. La urbe tiene a su alrededor un amplísimo territorio municipal, en el que se inscriben pueblos, aldeas y caseríos, envueltos en rocas, agua, vegetación, luz y aire que no son factores complementarios de la ciudad, sino esenciales. Y por ello, muy probablemente, ésta sea la más hermosa ciudad paisaje del mundo" (García Marchante, 2001: 17). Es uno de esos singulares casos de equilibrio entre lo natural y lo construido como demuestra la UNESCO en 1996 al declarar Patrimonio de la Humanidad al Casco Histórico y las Hoces que lo rodean (Aparicio y Fernández, 2004).

Josefina Gómez Mendoza, en su discurso de ingreso en la Real Academia de la Historia (Gómez Mendoza, 2003), defendió la necesidad de que el medio urbano tenga más en cuenta su entorno, resaltando que una de las condiciones de la calidad urbana y de los espacios públicos es el contacto con la naturaleza. En este sentido aboga por recuperar más la naturaleza y los procesos naturales, utilizar mejor la topografía y los recursos del medio ambiente y, en definitiva, artificializar menos la ciudad y el entorno para no perder su singularidad" (García Marchante, 2003: 183).

Según Ana Eulalia Aparicio y María Cristina Fernández, para comprender el emplazamiento y la morfología urbana de la ciudad tenemos que tener en cuenta el momento histórico en el que se fundó; el avance de la reconquista; las necesidades defensivas de los musulmanes; la decisión de instalarse en una mole caliza fácilmente defendible; el crecimiento demográfico consecuencia del auge económico; la estructuración de la ciudad cristiana a partir del Fuero otorgado por Alfonso VIII tras la Reconquista; las exigencias de la sociedad de carácter estamental en la que nobleza y clero controlaban el suelo urbano; la compactación urbana y el aumento de la altura de los edificios; el salto de la muralla ante la falta de espacio urbano; y el crecimiento urbano en todas las direcciones: hacia el norte (actual barrio del Castillo); hacia el este (barrio de Tiradores), hacia el oeste (barrio de San Antón), y hacia el sur (zona de ampliación en la ciudad baja). En las tres primeras, en zonas con elevadas pendientes, se instala la clase trabajadora; y en las cotas más bajas de la ciudad, en espacios más aptos para el uso residencial, la clase burguesa (Aparicio y Fernández, 2004).

En el sur, desde el pie de la Sierra del Bosque (1.089 metros) se aprecia el emplazamiento de Cuenca sobre un espolón cretácico que resalta las hoces labradas por los ríos Júcar y su afluente el Huécar en la Sierra de Bascuñana. Gustavo Torner califica esta visión de "topografía vestida de ciudad, ya que el 
caserío se desparrama desde la cima de los crestones cretácicos hasta el valle, como si se tratara de un material plástico que va rellenando todos sus huecos. El tejido urbano se adapta a la topografía como un vestido a un cuerpo" (Aparicio y Fernández, 2004, y García Marchante, 2011).

Considera Julián Marías que las hoces son partes de la ciudad porque solo desde ellas es accesible Cuenca, solo desde ellas se le puede ver. En otros lugares hay que salirse de la ciudad para verla. En Cuenca, seguimos en la ciudad y hay mil perspectivas y no todas son exteriores; siempre se está entrando y saliendo, se asoma uno a la ciudad desde fuera o desde dentro (García Marchante, 2013: 44).

$\mathrm{Al}$ oeste y este, las hoces confieren personalidad y singularidad al Casco Histórico al integrar el espacio exterior en la percepción del paisaje urbano. Ambas tienen a su vez ámbitos de homogeneidad en relación con aspectos formales, como la tipología constructiva, y funcionales, como el uso o la actividad.

En la hoz del Huécar, al este, espacio en el que están ubicados los museos de arte contemporáneo objeto de nuestro estudio, el caserío, adaptado a la topografía, ofrece variedad de formas y de volúmenes que reproducen las curvas de nivel. Los materiales utilizados son los proporcionados por el entorno, piedra en la mampostería y en la escasa sillería, madera en los entramados de los paramentos, suelos, cubiertas y balconadas situadas en las traseras, y finalmente el yeso en los revocos como vehículo de los pigmentos naturales. Los vanos pequeños e irregularmente dispuestos responden a unas condiciones climáticas duras y a la variada compartimentación del espacio interior acomodado al relieve. Los colores de sus fachadas, ocres, rosados, verdes, grises, etc., se corresponden con los de su entorno natural (Fernández, 1995: 368) (Figura 1).

Siguiendo a Kevin Lynch (1984), el mapa de la percepción geográfica se articula en sendas, nodos, hitos y bordes como referentes espaciales que ayudan a la lectura de la morfología urbana. En nuestro caso, los bordes se identifican con los dos niveles que presentan las hoces de los ríos, por un lado, la dolomía erosionada, relacionada con el paisaje exterior, por otro, el nivel humanizado y construido que eleva el conjunto y que se relaciona con el paisaje interior (García Marchante, 2013: 44).

Desde los jardines del Parador de Turismo y el Espacio Torner al otro lado de la hoz, se encuentran puntos de vista inmejorables de la fachada urbana orientada al este (Figura 2). De izquierda a derecha se suceden las Casas Colgadas (Museo de Arte Abstracto Español) -1-, la catedral -2-, la iglesia barroca de San Pedro -3-, el convento de las Carmelitas Descalzas (Fundación Antonio Pérez) -4-, y las antiguas fábricas del Tribunal de la Inquisición (Archivo Histórico Provincial) -5-, alternadas con el caserío. Los edificios se enriscan sobre los muros verticales del cañón, resultado de la angostura del terreno y la perpendicularidad del acantilado, que obligan a buscar los cimientos a gran profundidad, como en el 


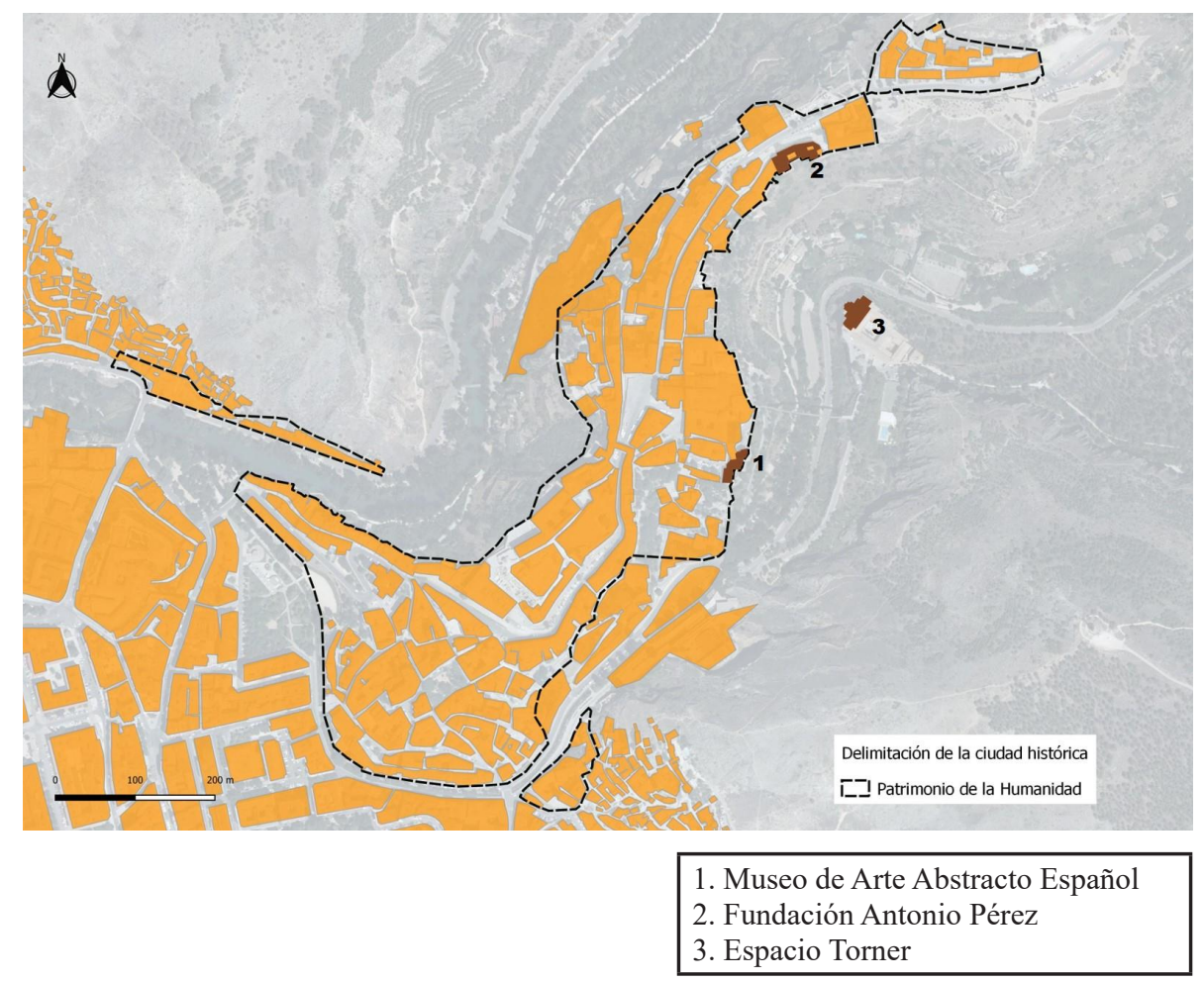

Figura 1.Localización de los museos de arte contemporáneo. Fuente: Cartovisual y PNOA. CNIG (IGN). Elaboración propia.

convento de las Carmelitas (Ibáñez, 1997: 11), edificio en el que se ubica la Fundación Antonio Pérez.

Otro tipo de construcciones son los "hocinos", denominación que reciben tanto los pequeños huertos de la ribera del río Huécar como las construcciones asentadas al pie de los escarpes calizos, algunas de las cuales se encuentran en un estado de abandono y prácticamente derruidas.

Si descendemos por el eje viario que da acceso rodado al Parador de Turismo, podremos observar otra perspectiva del escarpe calizo, ahora con otra tipología edificatoria: el barrio de San Martín, a la izquierda de las Casas Colgadas, al sur. Nacido en el siglo XVI, está constituido por dos conjuntos de edificaciones, uno en la cornisa de la Hoz del Huécar y otro al pie del escarpe. En el primero los edificios se organizan entre medianerías, sobre plantas muy alargadas y estrechas; se acomodan a los precipicios que los sustentan y se elevan colgados en el vacío de tal forma que presentan dos fachadas con distintas alturas: entre tres y cuatro alturas a la calle Alfonso VIII y hasta ocho en la cornisa al Huécar, con una particularidad, 


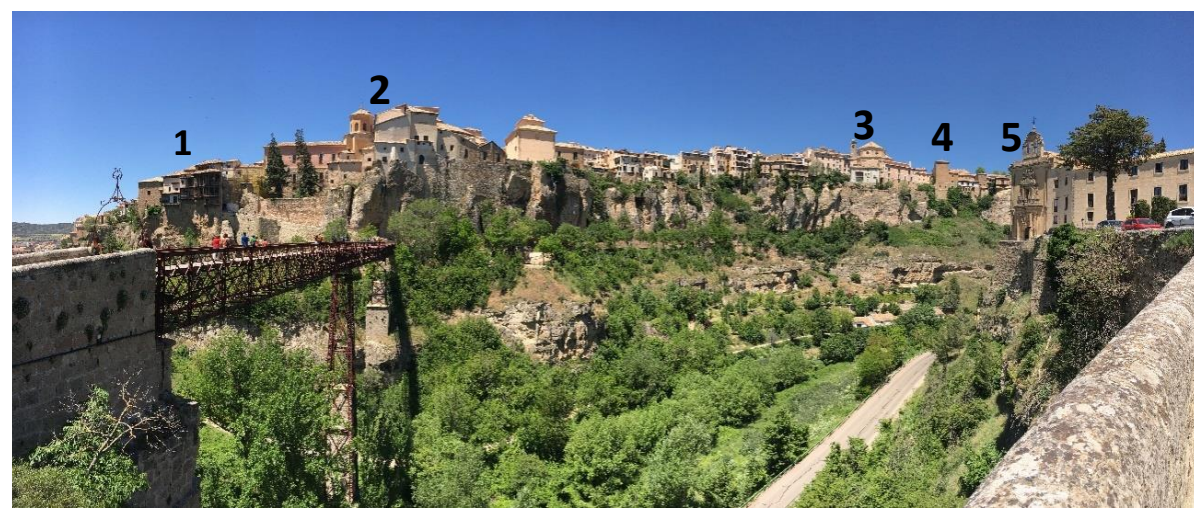

Figura 2. Cornisa del Casco Histórico a la hoz del Huécar. Fuente: Autores.

el reiterado vuelo de cada piso sobre el inmediato inferior. Son los denominados rascacielos de San Martín. El segundo conjunto presenta características rurales: edificios casi siempre de dos alturas realizados con procedimientos constructivos precarios, materiales pobres y ausencia de elementos de ornato en sus fachadas (Pol y Gago, 1983).

Desde finales del siglo XIX y comienzos del siglo XX, el barrio de San Martín es admirado por escritores que encontraban en el mismo rincones plenos de tipismo, belleza y poesía: Unamuno, Pío Baroja, Eugenio D’Ors, Alejo Carpentier, Torrente Ballester y Julián Marías, entre otros. Y lo mismo sucede con los artistas, que encuentran fuente de inspiración para sus cuadros, como sucede con el pintor canadiense William Henry o el pintor cubano Wifredo Lam (Ibáńez, 2018a).

\section{Planeamiento y políticas urbanas. Cambio de uso de antiguos} EDIFICIOS HISTÓRICOS. LA INSTALACIÓN DE EQUIPAMIENTO MUSEÍSTICO

En los años 60 y principios de los 70 el centro histórico de Cuenca se encontraba en una crítica situación: descenso demográfico, turistización y utilización lúdica, pérdida de funciones tradicionales, proliferación de residencias secundarias, expansión de la hostelería, e infrautilización de antiguos edificios religiosos.

Ya en 1954 se constituyó la delegación municipal "Cuenca Antigua" para luchar contra este problema y mantener la función residencial mediante el acondicionamiento del saneamiento, de los accesos y la conservación del caserío; y en 1963 se declaró Paraje Pintoresco el Casco Antiguo y todo el paisaje que lo rodea, con objeto de proteger tanto el Casco como sus alrededores, evitando construcciones o reformas inadecuadas.

La elección de Cuenca por pintores abstractos para instalar sus centros de trabajo, un grupo de artistas bajo el nombre de "El Paso" comandado por Zóbel, y la creación del Museo de Arte Abstracto Español, impulsaron el inicio de la 
revitalización del Casco Histórico de la ciudad desde el punto de vista turísticocultural (Aparicio y Fernández, 2004).

A partir de esos años, las intervenciones, tanto públicas como privadas, siguieron una trayectoria ascendente con resultados desiguales. Los equipamientos socioculturales han conocido un desarrollo importante en las tres últimas décadas gracias a la puesta en marcha de iniciativas nacionales, regionales y locales (Troitiño, 1992). Como respuesta a la sensibilización existente en los años 60-70 respecto a la necesidad de recuperar y rehabilitar los Cascos Históricos, la Dirección General de Arquitectura y Vivienda redacta en 1980, para la ciudad de Cuenca, el Plan Piloto de Rehabilitación del Barrio de San Martín. En 1988 la Junta de Comunidades de Castilla-La Mancha pone en marcha el programa "Cuenca a Plena Luz" con el objetivo de incentivar las actuaciones de rehabilitación de la iniciativa privada a través de la intervención pública (Aparicio, 1997). Junto a los subprogramas Rehabilitación de Viviendas, Mejora del Paisaje Urbano, Restauración Monumental y Redacción del Plan Especial, el subprograma Equipamiento Sociocultural se dirige a la recuperación de arquitecturas que ya no cumplen el destino para el que fueron construidas, asignándoles un nuevo uso y actividad, compatibles con esos viejos contenedores (Aparicio, 2004).

A "Cuenca a Plena Luz" le siguen el Proyecto Integral de Mejora Urbanística dirigida al Turismo (1994), el Plan de Dinamización Turística (1999), el Plan Especial del Casco Antiguo y las Hoces (2000), la creación de la Fundación Turismo de Cuenca (2004), el Real Patronato (2004), y el Consorcio de la Ciudad de Cuenca (2005). Estos dos últimos garantizan la adecuada coordinación de las distintas Administraciones y de éstas con los ciudadanos y la sociedad; y permiten acceder a subvenciones de cuatro Administraciones (central, regional, provincial y local) para conservar su patrimonio monumental y potenciar su actividad cultural y turística (Aparicio y Fernández, 2004; Almarcha, Díez de Baldeón, Peris y Sánchez, 2011).

El Proyecto Integral de Mejora Urbanística dirigida al Turismo 1994-1999 nació como uno de los instrumentos para desarrollar y financiar las propuestas del futuro Plan Especial de Protección, Ordenación y Mejora del Casco Antiguo y las Hoces. Sus objetivos se centraron en la mejora de la accesibilidad y movilidad peatonal, la renovación de las infraestructuras y pavimentos del casco antiguo, la construcción de aparcamientos para residentes y visitantes, la disminución del tráfico privado y el reforzamiento del transporte público, la supresión de barreras físicas, la recuperación las zonas urbanas degradadas, y la construcción de un centro de acogida de visitantes.

El Plan de Dinamización Turística, aprobado en 1998, inició su andadura en 1999 en un marco de cooperación interadministrativa siendo su objetivo principal preparar la ciudad, y especialmente su casco antiguo, como un destino atractivo y de calidad. Sus actuaciones se centralizaron en la mejora del producto; 
la promoción, comunicación y comercialización; y la gestión. Las intervenciones realizadas en el programa de mejora de producto se orientaron a preparar el patrimonio cultural como recurso turístico, y las principales actuaciones desarrolladas fueron: la eliminación de cableado aéreo en algunas calles; el plan de accesibilidad y movilidad peatonal; la rehabilitación de la iglesia de San Miguel; la readecuación y apertura del centro de artesanía; la adecuación del auditorio del Huécar como sala de congresos; y, como actuación estrella, el centro de recepción de turistas. En relación con la imagen de marca e identidad corporativa, la puesta en marcha del programa de promoción, comunicación y comercialización supuso una importante renovación de la imagen turística de la ciudad, hasta ahora la imagen de las Casas Colgadas, con el diseño de un nuevo logo. El programa de gestión ha permitido la firma de convenios formativos con universidades y la creación de la Fundación Cuenca Ciudad de Congresos para fomentar el desarrollo de la economía de Cuenca en materia turística.

El Plan Especial del Casco Antiguo y las Hoces fue aprobado en el año 2000 entrando en vigor en febrero del 2001. El estímulo de la función residencial y de una política de rehabilitación; el impulso del comercio relacionado con las funciones residencial, sociocultural, educativa y turística; el cambio funcional de edificios religiosos; el impulso del transporte colectivo; y el diseño de propuestas de peatonalización son algunos de los objetivos planteados en el mismo.

El Plan de Dinamización Turística de Cuenca y la Fundación Cuenca Ciudad de Congresos constituyen los antecedentes de la Fundación Turismo de Cuenca (2004), cuyo principal objetivo es la gestión integral del turismo de la ciudad y provincia mediante el turismo cultural, el turismo de reuniones y el turismo de naturaleza, además de promover en colaboración con la Universidad de CastillaLa Mancha el Observatorio Turístico de Cuenca.

Por último, el Real Patronato de la Ciudad de Cuenca fue creado mediante Real Decreto de 23 de enero de 2004 con el objetivo de conservar y revitalizar el Patrimonio Cultural de la ciudad, coordinar las inversiones que se proyecten por las Administraciones públicas, y promocionar iniciativas y proyectos culturales orientados a la conservación del patrimonio histórico y a la potenciación de la ciudad de Cuenca como lugar de encuentro de culturas diversas. Para gestionar y desarrollar las tareas derivadas de la ejecución de los acuerdos adoptados por el Real Patronato se cuenta desde el año 2005 con el Consorcio Ciudad de Cuenca.

Ejemplos significativos de rehabilitación con cambio de uso y la instalación de funciones museísticas son: 1) una intervención pionera en su tiempo, la rehabilitación con cambio de uso de un conjunto de edificios residenciales de la hoz del Huécar para albergar la colección de arte contemporáneo de Zóbel, y que constituiría el Museo de Arte Abstracto Español; 2) la rehabilitación del convento de las Carmelitas, en su día sede del Vicerrectorado de Extensión Universitaria de la Universidad de Castilla-La Mancha, Museo Internacional de Electrografía y 
Universidad Internacional Menéndez Pelayo, y actualmente Fundación Antonio Pérez; y 3) la adaptación de la iglesia del antiguo convento de San Pablo para instalar el Espacio Torner (Figuras 2 y 3 ).

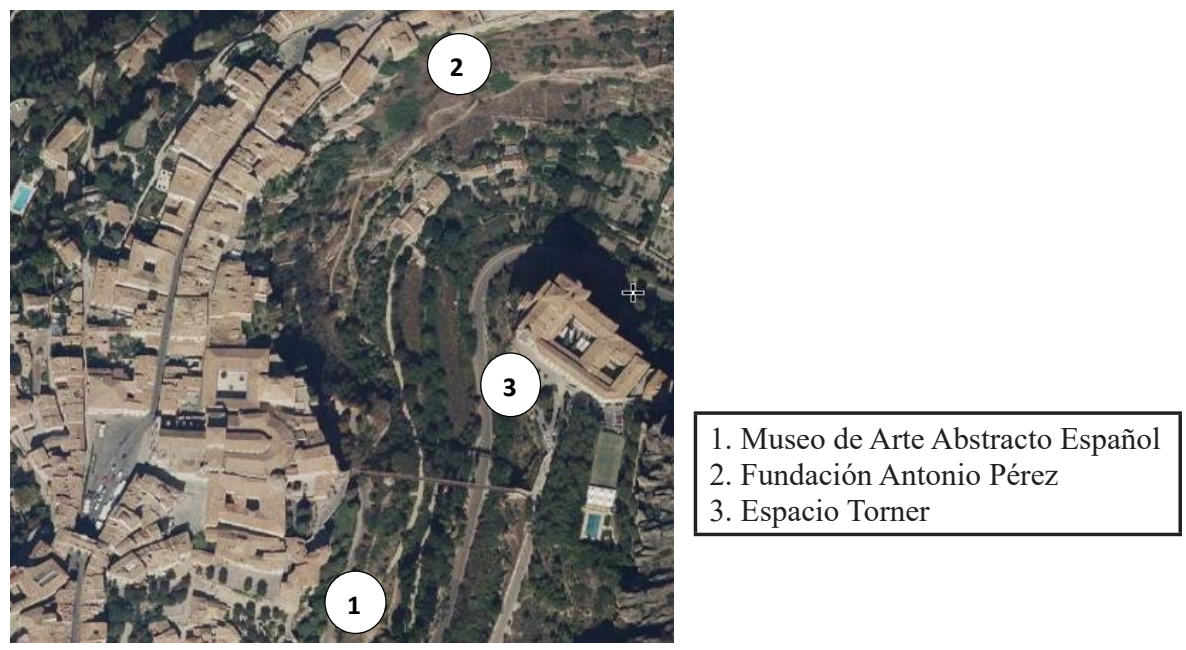

Figura 3. Los museos de arte contemporáneo en el paisaje urbano de la ciudad de Cuenca. Fuente: Comparador de ortofotos PNOA. CNIG (IGN). Elaboración propia.

A estas actuaciones hay que añadir la instalación del Museo Arqueológico en un edificio histórico próximo al Museo de Arte Abstracto Español; del Museo de las Ciencias de Castilla-La Mancha en lo que fue Asilo de los Desamparados; la reutilización del antiguo edificio de la Inquisición como Archivo Histórico Provincial; la adecuación del edificio de Palafox para sede de la Joven Orquesta Nacional; el acondicionamiento de la Casa Zabala para sede de la Fundación Antonio Saura; o la construcción de nueva planta de edificios como el Teatro Auditorio. En definitiva, durante los últimos años se ha producido una importante revalorización del paisaje y del patrimonio cultural.

\section{LOS MUSEOS DE ARTE CONTEMPORÁNEO}

\subsection{MUSEO DE ARTE ABSTRACTO ESPAÑOL}

Durante la segunda mitad del siglo XIX el deterioro de la parte alta de la ciudad de Cuenca afecta intensamente al Barrio de San Martín, y un buen número de sus casas se derribaron por lo que la cornisa sobre el Huécar quedó partida en dos. En este contexto de abandono poblacional y degradación física hay que situar la iniciativa de los propietarios de las casas números 14 y 16 de la calle Canónigos en 1905 y 1926, respectivamente, tendentes a destruirlas con el objeto de aprovechar los materiales constructivos. La oportuna intervención municipal 
llevó a la adquisición de estas dos casas que, junto a la de Las Sirenas, procedente de una permuta con el Obispado en 1928, y dos pequeñas casas compradas en 1965 constituyeron el actual conjunto de las Casas Colgadas (Troitińo, 1984: 623).

Para Pedro Miguel Ibáńez, el compuesto edificado conocido universalmente como Casas Colgadas de Cuenca, constituye una de las arquitecturas más singulares que puedan encontrarse en el patrimonio histórico de la vieja Europa. El nombre y la imagen de inmuebles modestos en sí mismos, han traspasado las fronteras en mayor grado que otros monumentos de carácter civil mucho más artísticos, monumentales y refinados, convirtiéndose en un icono urbano con proyección internacional y, finalmente, en un emblema de absoluta modernidad vinculado con el Museo de Arte Abstracto Español. Todo ello se ha producido en progresivas metamorfosis que han ido transformando su aspecto, pero sin menoscabar en grado alguno su potencia como imagen icónica de una antigua ciudad (Ibáńez, 2016a: 11).

El Museo de Arte Abstracto Espańol de Cuenca, inaugurado en 1966, tiene una historia cuyo origen se remonta a 1955, año en el que su fundador, Fernando Zóbel (Manila, 1924-Roma, 1984), durante un viaje a Madrid, descubre la pintura abstracta espańola en la Galería Fernando Fe. Tal y como indica Ángeles Villalba, la historia del museo camina en paralelo al quehacer artístico de una generación de pintores que dirigieron sus pasos hacia la abstracción en un contexto social, político y cultural adverso, escasamente receptivo a cualquier atisbo vanguardista. El museo fue un logro muy relevante, ya que supuso el reconocimiento de unos artistas ignorados por su propio país y, de modo especialmente significativo, por la forma de mostrar la colección al público (Villalba, 2006: 55).

En junio de 1963, Fernando Zóbel viaja a Cuenca a la casa del pintor Gustavo Torner, a quien había conocido en la Bienal de Venecia de 1962. Pronto el proyecto del museo toma forma cuando, a través de Gustavo Torner, el alcalde de Cuenca le ofrece el edificio de las Casas Colgadas, que en aquellos momentos estaba en restauración y cuya utilidad estaba aún por decidir, para instalar su colección. Al ver las Casas Colgadas, Zóbel se decidió inmediatamente, y con ello consiguió la transformación de su colección particular, de disfrute personal, en colección pública (Villalba, 2006: 58).

Además, con el museo, Fernando Zóbel no solamente se propuso reunir la mejor colección de abstractos españoles, sino que también pretendía convertir a Cuenca en el centro de reunión de estos artistas, algo que consiguió pronto. A finales de 1963 ya tenían estudio en Cuenca, además de Gustavo Torner y Antonio Saura, que ya vivían allí, Fernando Zóbel, Gerardo Rueda, Manuel Millares, Manuel Mompó y Amadeo Gabino (Villalba, 2006: 61).

Las Casas Colgadas conformaban una edificación muy singular. Formaban parte de un conjunto urbano, "una ciudad colgada", cuyas edificaciones pendían 
sobre la sima gracias a un peculiar sistema de andamiaje de vigas, denominado "almojaya". En 1927, se adosaron al viejo edificio unos teatrales balcones en voladizo que acentuaban el dramático efecto de la casa suspendida sobre el abismo de la hoz. Ese añadido no se concluyó y el edificio permaneció abandonado a la ruina hasta que en los años cincuenta se abordó la restauración, realizada por los arquitectos Fernando Barja y Francisco León Meler. El edificio como tal va a cumplir un papel decisivo en el carácter del museo, uno de cuyos atractivos será la convivencia, hasta entonces no muy explorada, de lo viejo, aportado por la fisonomía rústica del caserón, y lo más nuevo, la abstracción pictórica de los cuadros expuestos (Bolaños, 2006: 44-45).

Un gran rigor presidió la instalación de las obras, buscando en cada caso concreto la luz apropiada, el color y la textura del muro (Villalba, 2006: 71). El diseño de la arquitectura interior fue encomendado a Gustavo Torner, quien, con la colaboración de Gerardo Rueda, y con independencia de la calidad de la colección, convirtió al museo en una pequeña joya (Bolaños, 2006: 49).

Según María Bolaños, cuando se inauguró, el 30 de junio de 1966, el resultado no podía distar más de lo que se esperaba de un museo, aún más insólito en la tediosa realidad nacional. Se trataba de un museo pensado, diseñado y realizado por artistas, ajenos al ámbito del conservador-funcionario al uso, con la presentación de las obras al margen de criterios historicistas o cronológicos y su concepción como un museo solo contemporáneo. Todo era nuevo: esa escala doméstica a medio camino entre la privacidad de la vivienda de un coleccionista y el neutralismo de un museo público abierto a la vista. La arquitectura envolvente, ajena a las grandes galerías y paseaderos de los museos del pasado, los recorridos irregulares por distintos niveles y alturas entonaban con los pequeños y sabrosos descubrimientos deparados a la curiosidad del visitante (Bolaños, 2006: 45). El viejo edificio refuerza los atractivos de la colección creada por Fernando Zóbel. Su conformación aparentemente unitaria corresponde en realidad a inmuebles y épocas diversas. Constituyen tres edificios diferentes, y el visitante, al recorrer las salas, entra y sale de cada uno de ellos sin saberlo. Su recorrido laberíntico, el reducido tamaño de las estancias y la disposición piramidal provocan que el visitante descubra algo nuevo en cada recorrido. Es lo más opuesto que se pueda imaginar a la estructura de grandes salas en hileras de la mayoría de los museos contemporáneos que conducen a la monotonía y al tedio (Ibáñez, 2016b: 36).

Tal y como afirma Pedro Miguel Ibáńez, se ha evocado el Museo Guggenheim de Nueva York por la disposición en espiral, asociando este efecto con la arquitectura tradicional de las propias Casas Colgadas. El Museo de Arte Abstracto Español de Cuenca se va descubriendo poco a poco en cada recodo, como en un juego de sorpresas continuas. Mucho tienen que ver con ello los inmuebles de origen antiguo en que se asientan, y el talento con el que el arquitecto Francisco León y los artistas que estuvieron con él en la definitiva rehabilitación de los espacios, 
supieron amoldar la reconstrucción de la casa del centro a los edificios colindantes (Ibáñez, 2016a: 362-363).

Para María Bolaños, las condiciones de exposición, es decir, la atención a la arquitectura, la luz o las cualidades del espacio mismo, ocuparon un papel de primer orden. Destaca el aislamiento físico de las obras, con el fin de que el espectador "las saborease" una a una, a la vez que iba deduciendo el diálogo que se establecía entre ellas por su proximidad relativa (Bolańos, 2006: 50).

Frente a esta intimidad se contrapone la presencia del paisaje que, con su bronca aspereza, se cuela por las ventanas y constituye uno de los secretos de la austera trascendencia que despide la visita al museo (Bolaños, 2006: 50). Según Pedro Miguel Ibáńez, la relación que se establece entre el museo y el entorno natural que lo rodea no pasa desapercibida para nadie, tanto desde el exterior como recorriendo sus salas y contemplando las vistas del paisaje de la hoz del río Huécar, enmarcadas en las ventanas y miradores del museo (Figura 4). Las vistas más representativas se localizan de manera particular en las dos salas de la casa del centro que dan a la hoz, y en la sala blanca de la casa de la bajada. El paisaje constituye en numerosos ámbitos expositivos un contrapunto a las obras de arte. Incluso, puede llegar a convertirse en un cuadro más de las salas. El paisaje natural encuadrado por sus balcones y ventanas armoniza con el legado estético que albergan sus salas (Ibáñez, 2016a: 359-360).

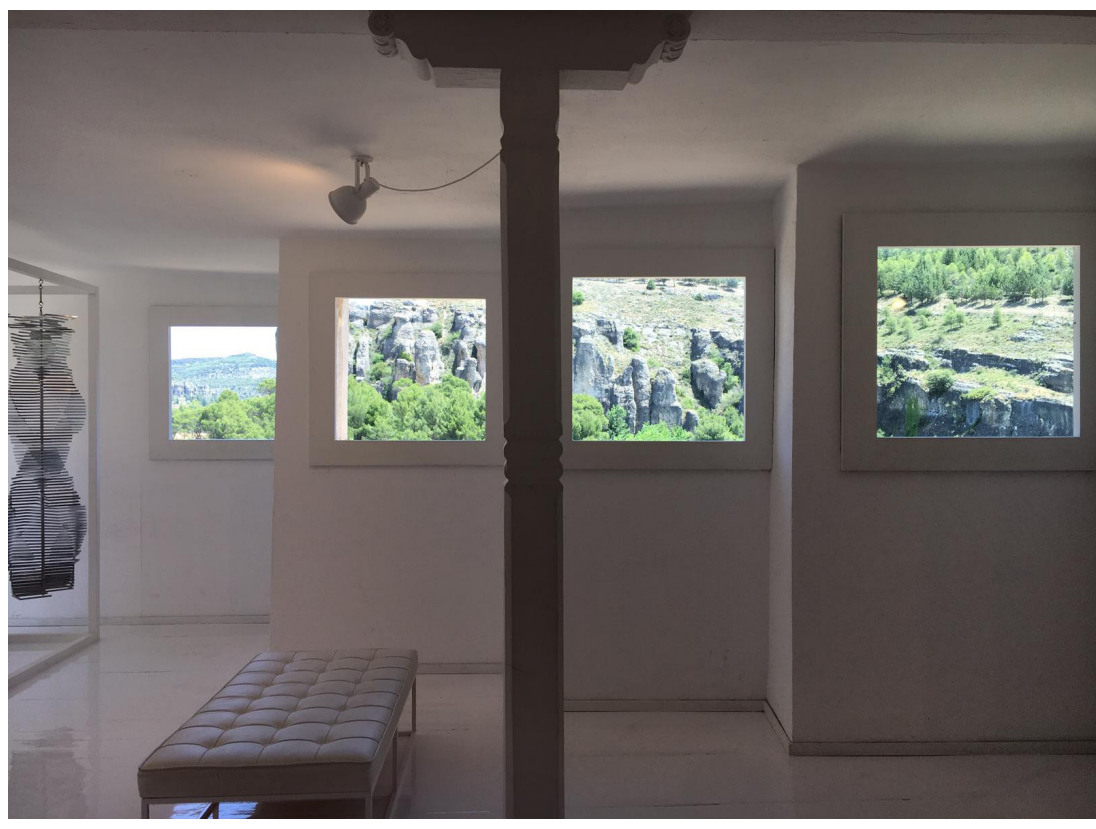

Figura 4. Ventanas-cuadro de la sala blanca del Museo de Arte Abstracto Español. Fuente: Autores. 
El museo contaba con una de las más arriesgadas y prestigiosas colecciones privadas de arte contemporáneo, y también con el hecho de haber asentado una fuerte identidad provincial sobre un intenso sentido del cosmopolitismo. Gracias a esto despertó la simpatía y la curiosidad de artistas, críticos y directores de museos, europeos y americanos, ansiosos de ver no solo la colección y su instalación en las Casas Colgadas, sino el ambiente artístico de una ciudad de pintores (Bolaños, 2006: 52). Unos meses después de su inauguración lo visitó Alfred H. Barr, fundador y primer director del Museo de Arte Moderno de Nueva York, quien manifestó que el museo le parecía "El pequeño museo más hermoso del mundo",... "seguramente una de las más admirables y brillantes obras de arte: un equilibrio notable en pintura, escultura y arquitectura" (Fontán, 2018).

El espacio disponible quedó pronto insuficiente, debido a que Zóbel continuó adquiriendo obras de las nuevas generaciones. Por ello se llevó a cabo una ampliación del museo, con la construcción de un nuevo edificio adosado al primitivo, con proyecto de Gustavo Torner y del arquitecto Fernando Barja, que quedó abierto en 1978 (Villalba, 2006: 76-77). Uno de los objetivos de la ampliación, de nuevo dirigida por Torner, es el de preservar el equilibrio entre arquitectura y paisaje. Para ello el nuevo edificio es mimético con el entorno, pero no será completamente ortodoxo en cuanto a la arquitectura histórica se refiere (Figura 5). De hecho, durante la etapa de ampliación se coloca una portada renacentista, procedente de un palacio en ruinas situado en Villarejo de la Peñuela, como único elemento decorativo valioso de la actuación, para dotar de valor simbólico al conjunto, lejos del rigor histórico (Galisteo, 2015).

Para Miguel Ángel Troitiño, la ampliación del museo en 1978 tiene el mérito urbanístico de cerrar por el este la plaza de Ronda y crear un ambiente más acorde con las necesidades de un lugar de encuentro, y justifica la instalación de la portada del Palacio de los Marqueses de Valdemediano en el carácter cultural que tiene el sector donde ha sido ubicada (Troitińo, 1984: 626) (Figura 6).

En 1981, Zóbel, preocupado por el destino futuro del museo, decidió su donación a la Fundación Juan March. Donó la colección sin establecer estipulaciones al respecto, ya que confiaba plenamente en la futura gestión del Museo por parte de la Fundación (Villalba, 2006: 79). Es lo que Javier Gomá ha calificado como "un hecho singular en la historia del coleccionismo espańol: era la primera vez que una colección privada no pasaba a ser patrimonio del Estado, sino que era donada a una institución privada del ámbito de la cultura, que daba continuidad e intensificaba la vocación de servicio público que había tenido la colección desde que hasta su entonces propietario había empezado a imaginarla" (Jiménez, 2013: 74).

En 2016 se cumplió el cincuenta aniversario de la apertura del Museo. Con ocasión de la cesión por el Ayuntamiento de una sala que ocupaba hasta hace algunos años el Mesón Casas Colgadas, la Fundación Juan March amplía los 


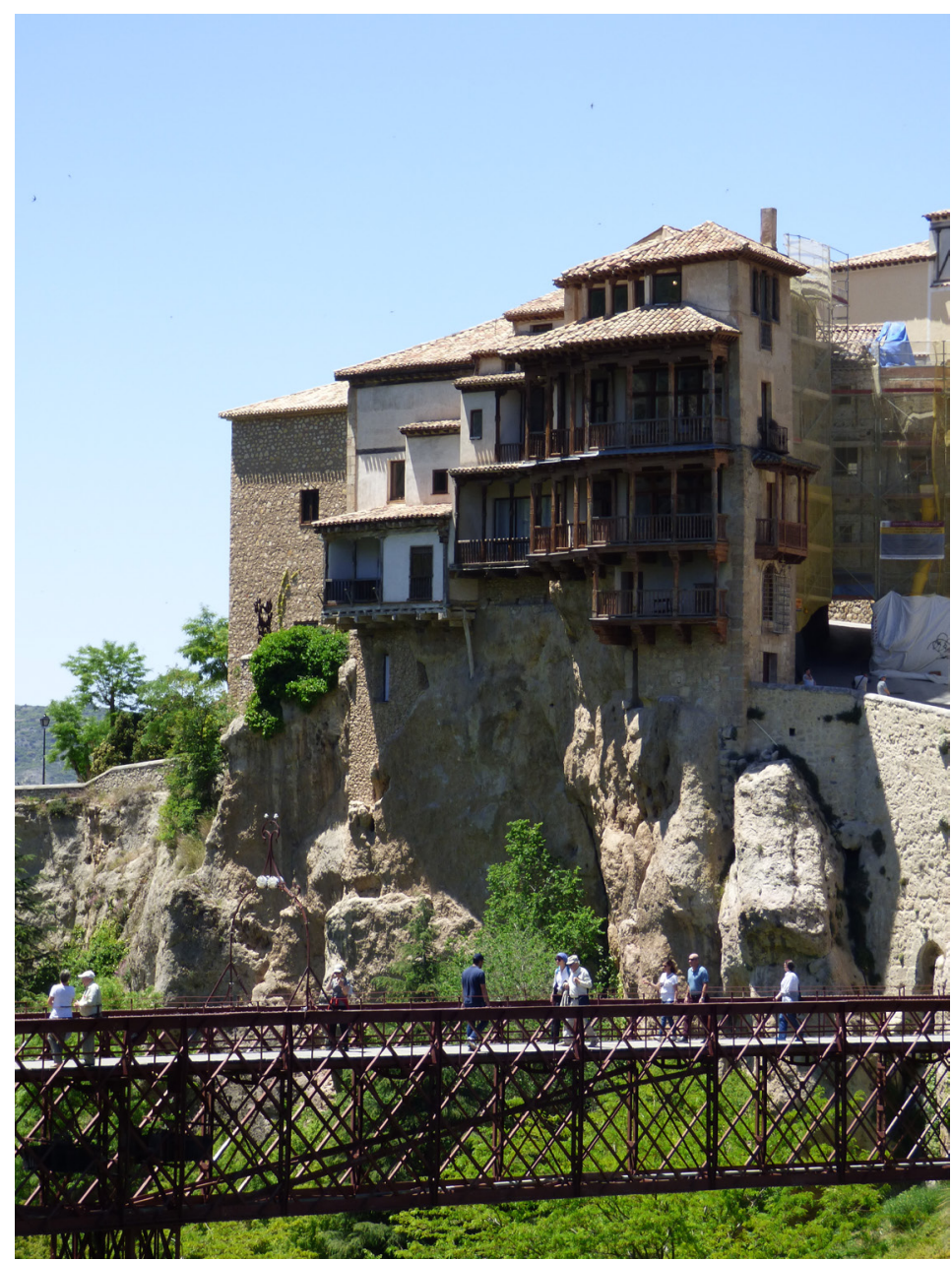

Figura 5. Museo de Arte Abstracto Español en las Casas Colgadas. Fuente: Autores.

espacios destinados a la exhibición permanente y temporal de su colección. Se reforman, modernizan, reordenan y ganan para uso público espacios destinados a administración, entre ellos algunos de los que conservan restos históricos de la fábrica original del siglo XV, y que ya habían sido utilizados para exponer obras de arte en 1966. Se dedica un espacio amplio al taller pedagógico. El museo recupera espacios polivalentes destinados a su biblioteca de investigación, a la biblioteca personal legada por Fernando Zóbel y al archivo histórico del museo, así como otros ámbitos de uso diverso para sus actividades y sus colecciones de obra gráfica y libros de artista (Fundación Juan March, 2016: 179). 


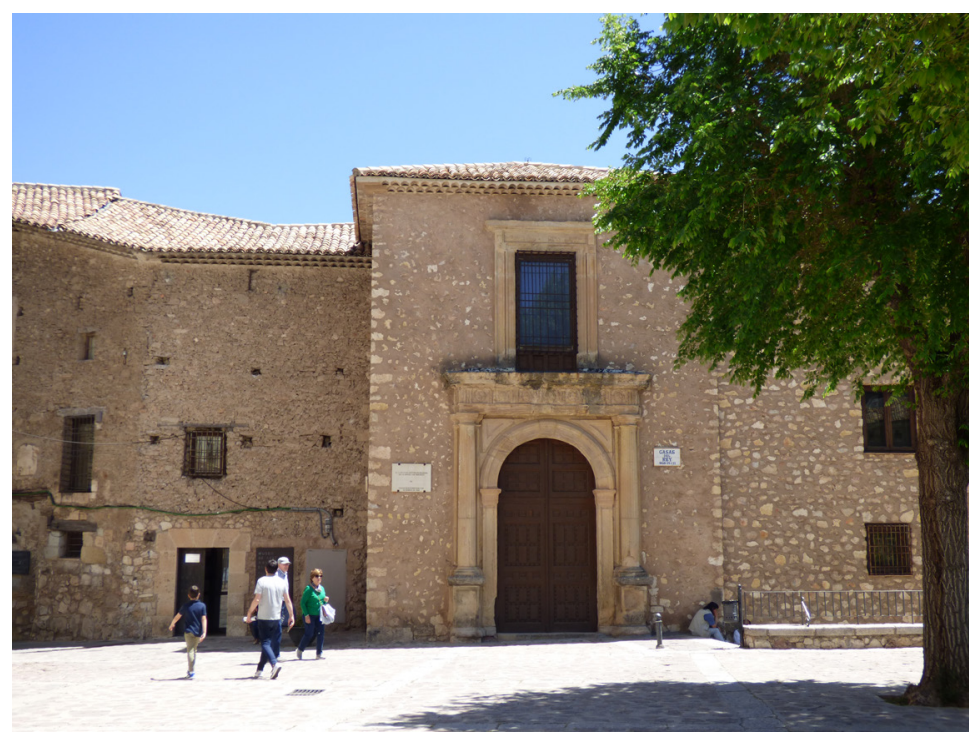

Figura 6. Museo de Arte Abstracto Español en las Casas Colgadas. Fuente: Autores.

Además de un proyecto generacional, el museo de Arte Abstracto Español debe entenderse como una excepción en lo referente al coleccionismo, con estándares de calidad elevados y capacidad de proyección nacional e internacional (Lorente, 2008). Por eso fue un acontecimiento excepcional en su época y pionero de la prosperidad alcanzada por los museos monográficos y especializados en artistas o tendencias concretas del arte contemporáneo (Layuno, 2002). Estamos ante uno de los más claros precedentes del museo de masas en la España franquista, cuyo mayor reclamo va a ser él mismo, su estampa, su ubicación. Un ejemplo de museo modélico donde nada se va a dejar a la improvisación, donde todo va a ser fruto de la planificación (Galisteo, 2015).

Cuenca ha jugado un papel en el gran cambio que ha experimentado España en las últimas décadas. El Museo de Arte Abstracto Español fue y es, esencialmente, un museo de artistas y un museo democrático, el primero de su tipo en España, veinte años antes de la vuelta a la democracia (Fontán, 2019). En esta línea también lo define Alfonso de la Torre, como "Nuestro primer museo democrático, pues supuso la elevación de la inteligencia de lo privado capaz de proveer estructuras casi públicas, algo capital durante la inane postguerra y hasta llegada la desgarbada proliferación museística contemporánea”."

En cuanto a la afluencia de visitantes al Museo de Arte Abstracto Español, en el año 2003 recibe 34.000, y de ellos el 16\% son extranjeros; cifra reseñable

1 https://www.delatorrealfonso.com/2016-arteinformado/ 
si tenemos en cuenta que ese ańo la población de la ciudad asciende a 47.201 habitantes, lo que supone 0,72 visitantes al museo por cada habitante de la ciudad. Este índice es muy aproximado al del Museo del Prado $(0,74)$, que recibe 2.318.525 visitantes en Madrid, que cuenta ese ańo con un censo de 3.124.892 habitantes (Galisteo, 2013). Tras la reforma del año 2016 duplica el número de visitantes respecto al año 2015, al pasar de 29.861 a 60.210. Trinidad Vacas y Paula María de la Fuente consideran como posibles causas de este incremento: en primer lugar, el precio de la entrada (ahora es gratuita para todos los públicos); en segundo lugar, la reforma que ha permitido crear espacios más grandes y ofrecer mejores servicios al visitante y; en tercer lugar, las exposiciones temporales, que desde 2016 conmemoran el 50 aniversario del museo, así como a su creador (Vacas y De la Fuente, 2016).

\subsection{FundACIÓN ANTONIO PÉREZ}

El Convento de las Carmelitas Descalzas de Cuenca fue diseńado en 1614 por el arquitecto carmelita fray Alberto de la Madre de Dios (Santander, 1575-Pastrana, 1635). De sus amplios trabajos en el obispado de Cuenca, esta obra corresponde a su primera etapa en la que el clasicismo, desposeído de cualquier tipo de ornamentación, roza la austeridad absoluta (García Martínez, 2015).

Este edificio presenta una planta alargada y estrecha, insertada entre la calle Ronda de Julián Romero y el barranco que se precipita hacia la hoz del río Huécar. Con la iglesia en el centro, se extiende a derecha e izquierda en torno a tres patios: uno porticado, el claustro con galería de balcones hacia su interior, abierto hacia el río Huécar; otro de grandes proporciones, también abierto hacia la hoz; y el tercero, más pequeńo y cerrado en todo su perímetro. El edificio cuenta con tres alturas sobre el suelo y otras tres bajo el nivel de este, aunque solamente en la planta baja está edificado todo el solar (Díaz Martínez, 2015).

Según Pedro Miguel Ibáńez, para la construcción de su iglesia se reservó una hendidura en el acantilado, con el fin de ganar un poco de espacio a costa de bajar los cimientos casi hasta el nivel de base de las rocas. Ello exigió un esfuerzo económico ańadido y una solución edificatoria imaginativa. Se alza así ese altísimo paredón. La obra humana compite con la de la naturaleza, en una espléndida integración de ambas (Ibáńez, 2001) (Figura 7).

Para Ibáńez, estamos ante un ejemplo de la arquitectura espańola de la época, entroncada con el clasicismo post-herreriano. Como hecho relevante, el suelo de la iglesia queda colgado literalmente mediada la perpendicular del monumental muro de sillería. La misma escasez de espacio explica tal vez que la iglesia carezca del habitual vestíbulo porticado de las fachadas de la orden (Figura 8).

Ante el deficiente estado de conservación y la imposibilidad de la comunidad religiosa de afrontar los gastos de su rehabilitación, fue cedido a la Diputación Provincial en 1978 a cambio de la construcción de otro nuevo en las afueras de la 
A. E. Aparicio Guerrero • C. Espejo Marín

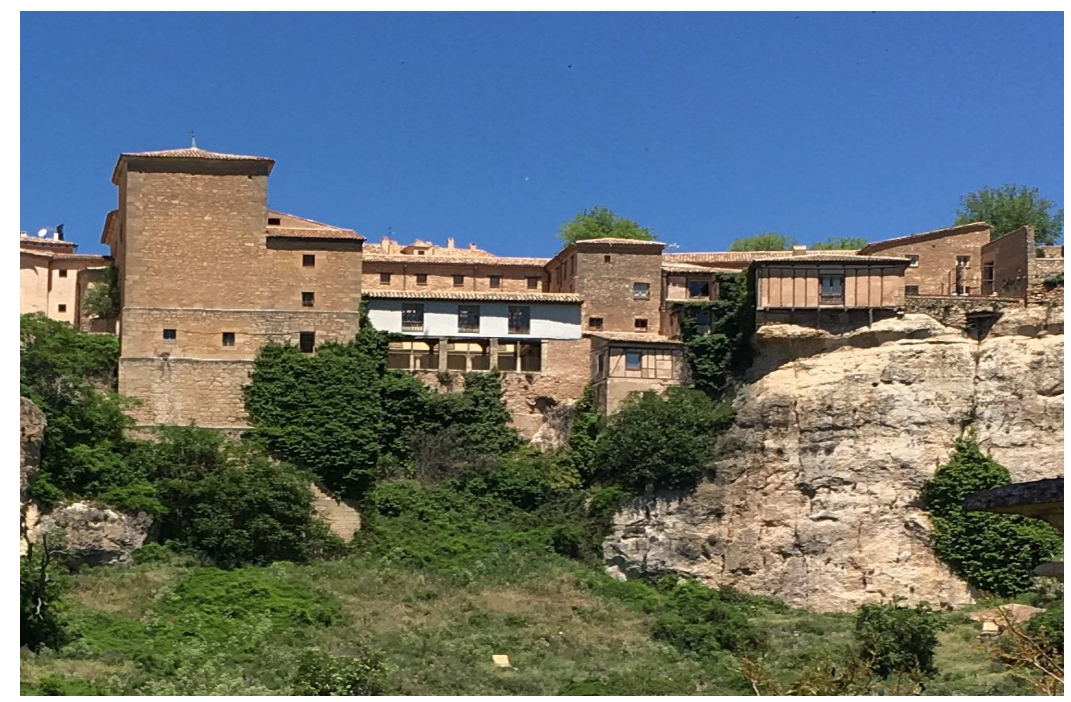

Figura 7. Fundación Antonio Pérez. Fuente: Autores.

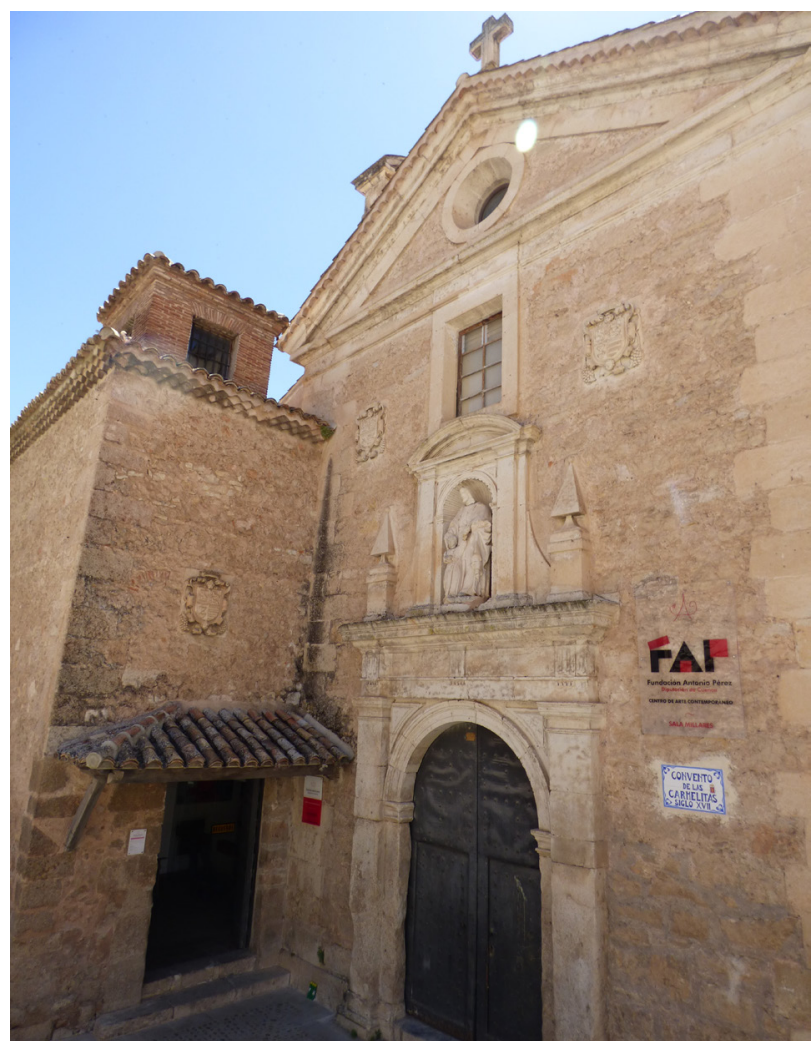

Figura 8. Fundación Antonio Pérez. Fuente: Autores. 
ciudad. Tras una fuerte inversión se convirtió en sede conquense de la Universidad Internacional Menéndez Pelayo y del Vicerrectorado de Extensión Universitaria de la Universidad de Castilla-La Mancha.

Posteriormente se realizó una segunda intervención para la adaptación del edificio al nuevo uso como museo de arte contemporáneo, con el principal objetivo de dejar los espacios diáfanos para facilitar el recorrido al visitante (Muñoz, 2018). En 1998, la Diputación de Cuenca destina el edificio para albergar la colección donada por Antonio Pérez y se constituye su fundación. La Fundación Antonio Pérez consta de un total de 35 salas repartidas en 4 plantas. En el museo se expone una parte de los fondos de la colección, que cuenta actualmente con más de 4.000 obras sin incluir la colección de Objetos Encontrados de Antonio Pérez. Dentro de la Fundación también se encuentran tres espacios destinados a exposiciones temporales que en intervalos de dos o tres meses se van celebrando regularmente. Uno de estos espacios es la antigua iglesia del edificio, que permite exponer las obras de gran formato. También hay que indicar que la Fundación cuenta con una biblioteca en la que se refleja el espíritu coleccionista y el amor que Antonio Pérez ha mostrado a lo largo de su vida por una de sus grandes pasiones: los libros (Muñoz Bascuñana, 2018).

Un estudio realizado por S. Yubero, E. Larrañaga y J. Carrascosa (2010), utilizando como base la información recogida en un cuestionario respondido por 618 visitantes a lo largo de un ańo, indica que estaban altamente satisfechos con las colecciones y la estructura física de la Fundación Antonio Pérez.

\subsection{ESPACIO TORNER}

El Convento de San Pablo es un edificio situado extramuros de la ciudad, en su parte oriental. Su diseño responde a unos planteamientos propios de los primeros ańos del siglo XVI: una estructura gótica y una decoración renacentista. A principios del siglo XX fue cedido por el Obispado de Cuenca a los Padres Paules, que instalaron en él su Seminario de Filosofía y Teología. A principios de los años 60 la iglesia fue recuperada para destinarla a sede de las semanas de Música Religiosa, uno de los festivales más antiguos de Espańa que empezó a celebrarse en 1962 coincidiendo con la Semana Santa, y a actividades culturales. Con la reutilización del antiguo edificio como Parador de Turismo en 1993, estas celebraciones pasaron a conmemorarse en el Teatro Auditorio.

La Iglesia de San Pablo, perteneciente al Convento de Dominicos contiguo y actualmente Parador de Turismo, comenzó a construirse en 1523; es un edificio tardo gótico con elementos renacentistas (Frayle, 2018). Además de por sus trazas y su sólida volumetría destaca por su emplazamiento excepcional (Figuras 9 y 10), por su "espectacular asentamiento en un punto crítico del paisaje conquense, aislado y enfrentado al impresionante conjunto de la ciudad medieval, en medio del vacío, como arrojado y atrevido centinela sobre un alto y accidentado saliente 


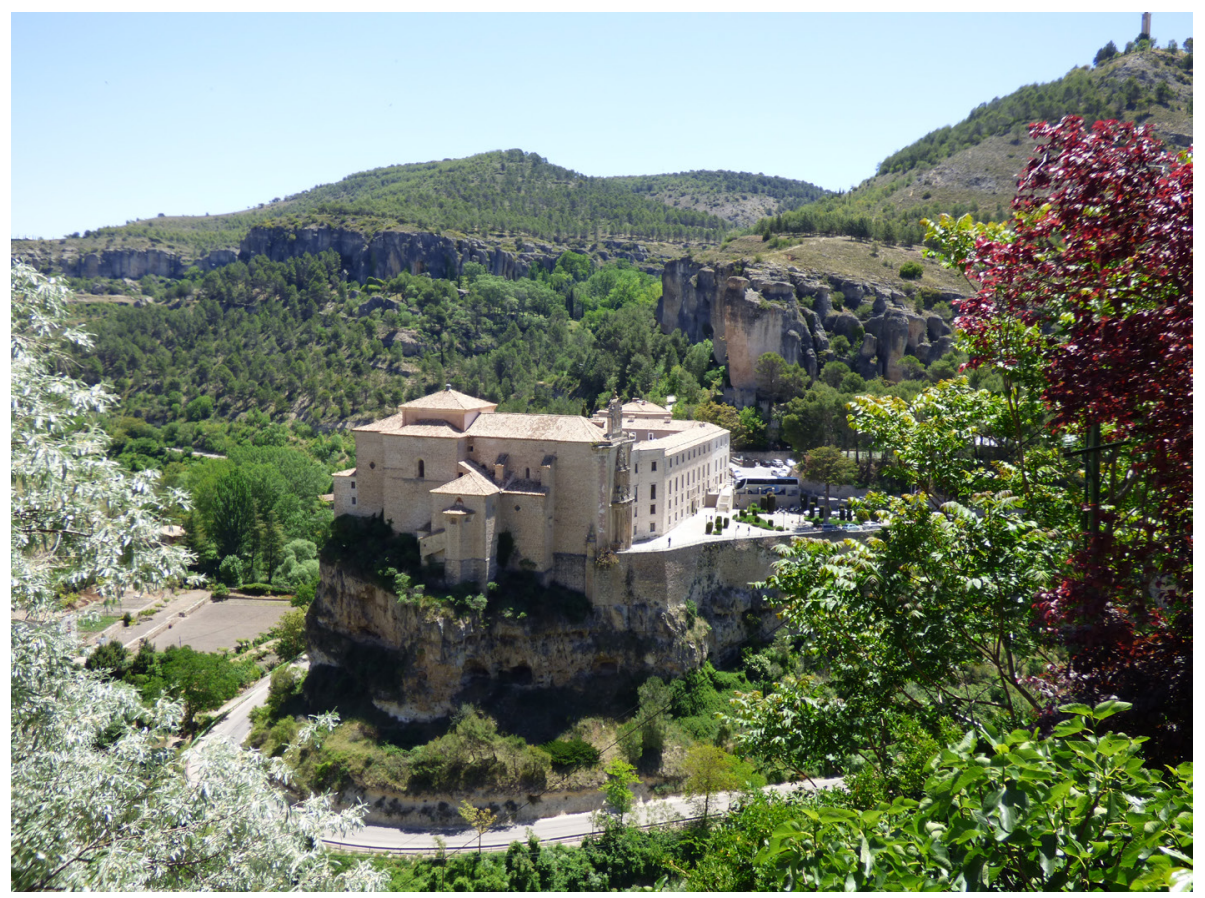

Figura 9. Espacio Torner. Convento de San Pablo. Fuente: Autores.

-al borde mismo del abismo- de la otra margen, la margen izquierda de la hoz del Huécar, frente a las Casas Colgadas y la casa-estudio del artista" (Sagastibelza, 2006: 13-14).

A comienzos de abril del año 2005, Gustavo Torner entrega al Museo Reina Sofía 561 obras (54 pinturas, 338 dibujos, 112 grabados, 40 collages, 16 fotografías y 1 escultura). De ellas, 30 piezas «muy especiales» serán cedidas para el espacio resultado de la rehabilitación de la iglesia del Convento de San Pablo, transformándose en lo que se conoce como Espacio Torner. Un proyecto que, según Torner, responde a una intuición porque "La intuición también es pensamiento". Para el artista, "La palabra museo no se ajusta a este proyecto". "Se trata de un espacio donde caben relativamente pocas obras, pero donde habrá una complementariedad entre continente y contenido. El resultado será más que la suma de dos. Será un lugar que no mezcle lo económico con lo espectacular. Un lugar para que la gente descubra que el arte es una cosa especial, una cosa que hacemos los humanos y que, aunque no es compensatoria ante tantas cosas horribles que nos rodean, nos deja atisbar otra medida del hombre y la humanidad" (Fernández Santos, 2004).

Esta importante donación de Gustavo Torner al Museo Nacional Centro de Arte Reina Sofía lleva a la Dirección General de Bellas Artes y Bienes Culturales, 


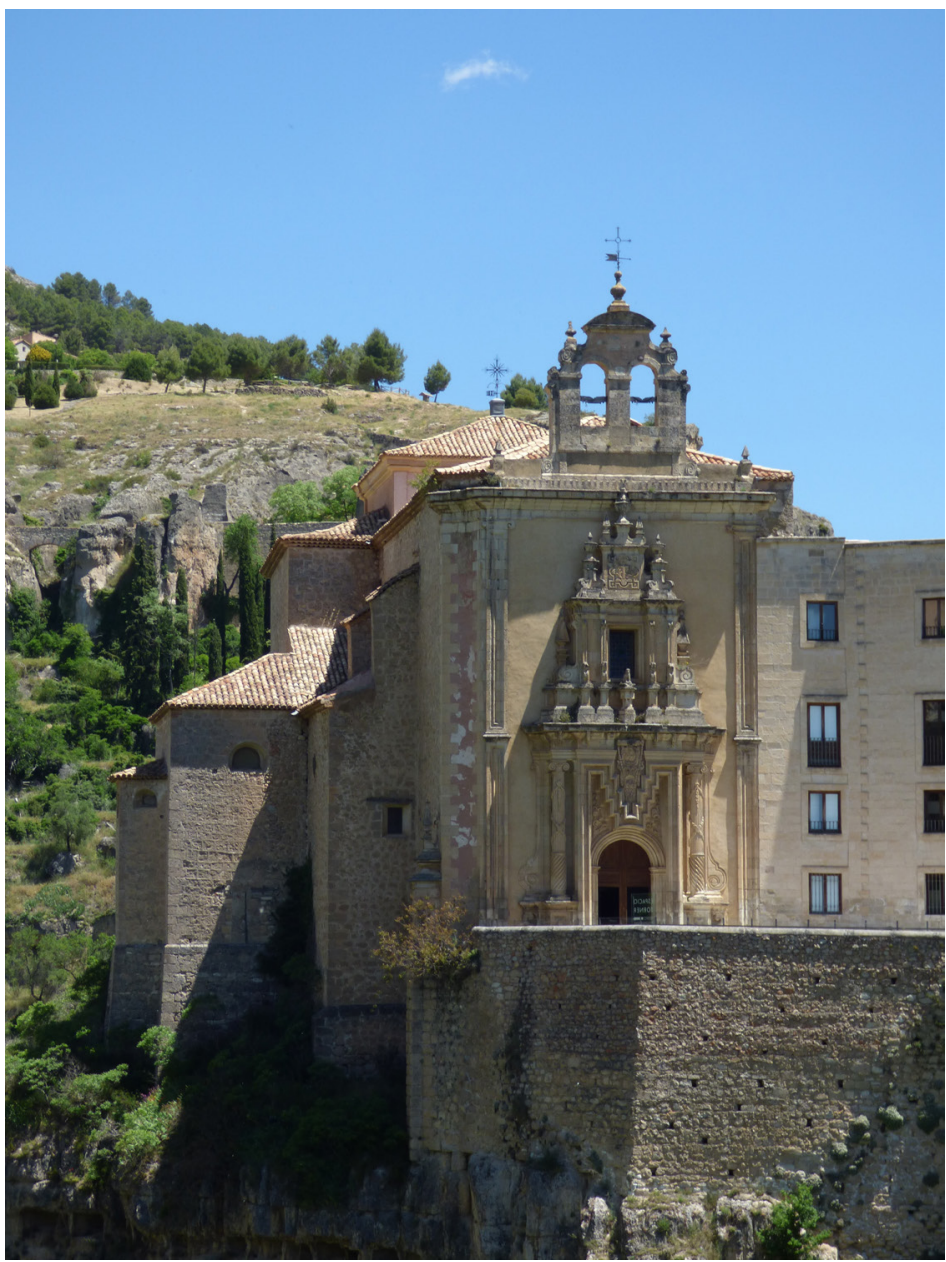

Figura 10. Espacio Torner. Convento de San Pablo. Fuente: Autores.

del Ministerio de Educación Cultura y Deportes, a plantear la iniciativa de crear un museo dedicado a su obra. Proyecto que, tras el acuerdo alcanzado entre Arzobispado, Ministerio y Fundación Torner, culmina en 2005 con la apertura del Espacio Torner en el privilegiado emplazamiento de la antigua Iglesia de San Pablo. Esta insólita ubicación ha sido posible ya que desde 1974 el templo quedó definitivamente sin culto, siendo esporádicamente utilizado como sala de actos culturales y conciertos durante la Semana de Música Religiosa de Cuenca (Sagastibelza, 2006: 14).

Para Arturo Sagastibelza, la más evidente singularidad de este museo, el uso de un antiguo templo gótico como espacio expositivo permanente, salta a la vista por los valores histórico-artísticos de la propia arquitectura, que constituye un 
aliciente más a la colección expuesta. La nobleza del interior, por su altura y proporciones, por sus bóvedas de crucería estrellada sobre la austera desnudez de los muros, libres de cualquier ornamento o atributo litúrgico, proporciona un continente casi perfecto a las obras que acoge. El trabajo conjunto del equipo de arquitectos Paredes-Pedrosa y el propio artista permitió dotar al museo de la infraestructura necesaria, partiendo de un respeto absoluto tanto a la tipología estructural como a los elementos físicos conservados (Sagastibelza, 2006: 15). Esta actuación (García de Paredes, A., García Pedrosa, I. y Torner, G., 2007) recibió en 2006 una Mención Especial en los Premios de Patrimonio Europeo que concede la Federación de Asociaciones e Instituciones de Patrimonio, Europa Nostra $^{2}$.

Actualmente, en el Espacio Torner se conservan y exponen en torno a cuarenta pinturas y esculturas abstractas que "dialogan con el receptáculo arquitectónico, conformando una unidad espacial de carácter metafísico a través del cual el espectador puede adentrarse en el estilo de pensar y la concepción del mundo que tiene su autor, como ser humano enfrentado a la inmensidad de la naturaleza" (Frayle, 2018).

Pese a la relevancia de este centro de arte contemporáneo, ha estado cerrado por problemas económicos entre noviembre de 2011 y marzo de 2016. En el diario Las Noticias de Cuenca se informa, con fecha de 26 de febrero de 2018, que una subvención del Ministerio de Cultura garantiza el Espacio Torner, que se uniría a otra similar del Consorcio de la Ciudad. También se informa que en junio de 2017 el pleno de Ayuntamiento aprobó iniciar los trámites para aceptar la donación de las obras de Gustavo Torner que ofreció a esta Administración a cambio de mantener abierto el Espacio Torner ${ }^{3}$. En su web ${ }^{4}$ se detallan los agradecimientos a: Ayuntamiento de Cuenca, Consorcio de la Ciudad de Cuenca, Ministerio de Cultura, Diputación Provincial de Cuenca, Museo Nacional Centro de Arte Reina Sofía, Obispado de Cuenca, Fundación Juan March, Ibercaja y STAI.

Como bien señala María Ángeles Layuno, un problema crónico de los museos españoles ha sido y sigue siendo la escasez de medios para llevar a cabo la programación de actividades requeridas por la sociedad actual o para abordar una adecuación museográfica digna y acorde con los nuevos tiempos (Layuno, 2002). Cabe esperar que no se vuelva a repetir la situación vivida por el Espacio Torner, y que tanto las Administraciones como la búsqueda del patrocinio privado permitan que siga reluciendo en Cuenca este lugar de referencia del arte contemporáneo universal.

2 http://www.paredespedrosa.com/works/60-espacio-torner/.

$3 \mathrm{http}: / /$ www.lasnoticiasdecuenca.es/cultura/subvencion-del-ministerio-garantiza-espaciotorner-33227

4 https://www.espaciotorner.es/ 


\section{Conclusiones}

El cambio radical de la imagen de una ciudad y su revitalización económica a partir de un museo de arte contemporáneo, cuenta en Bilbao con el mejor ejemplo internacional, En este caso, la regeneración urbana a través de la cultura no viene dada por su planificación, sino por el enorme éxito del edificio del museo Guggenheim para construir capital simbólico y convertir a la ciudad vasca en uno de los referentes culturales, arquitectónicos y turísticos del mundo.

La ubicación de los museos de arte contemporáneo en áreas de alta centralidad en edificios históricos va más allá de la creación de capital simbólico, y los convierte en instrumentos de apoyo a los procesos de regeneración de las áreas urbanas centrales, asociados a la capacidad para generar atracción económica y residencial, y, por lo tanto, de potenciar la recuperación de áreas urbanas degradadas. Se trata de que estas nuevas funciones de alto valor y simbolismo atraigan a su entorno tanto actividades relacionadas (galerías, fundaciones, academias, escuelas, comercio especializado), como otras conexas (restaurantes, hoteles, comercio de lujo, etc.) con el fin de servir al público especializado (artistas, críticos, aficionados al arte) y a los visitantes ocasionales y turistas, así como a las potenciales nuevas localizaciones que se vean atraídas por este tipo de usos. Los museos localizados en ciudades pequeńas como Cuenca, sin una clara imagen turística, las han situado en circuitos especializados.

Los museos de arte contemporáneo transmiten ideas eminentemente positivas ligadas a la modernidad, el vanguardismo o la capacidad de innovación (Barrado, 2012). Es evidente que en Cuenca ha sido la cultura el principal motor de la revitalización de su Casco Histórico; de hecho, fue la intervención en varias casas de la cornisa del Huécar y la instalación en ellas del Museo de Arte Abstracto Español, el punto de inflexión en la consideración de este espacio urbano por parte de la Administración y de la sociedad en general. Además, la fachada trasera del museo, con sus balconadas de madera, pronto se erigió en la imagen de la ciudad, su imagen de marca, uno de los hitos más conocidos de la localidad junto con otros museos ubicados en el Casco Histórico como el de la Fundación Antonio Pérez en el antiguo convento de las Carmelitas, también en la hoz del Huécar, o el Espacio Torner en la iglesia del antiguo Convento de San Pablo en la misma hoz, pero al otro lado del río.

Fueron las Casas Colgadas, la fachada trasera del Museo de Arte Abstracto Español, la imagen de marca de la ciudad hasta que los redactores del Plan de Dinamización Turística, en el marco del Programa de Promoción, Comunicación y Comercialización, plantearon la renovación de la imagen turística de la ciudad e identidad corporativa diseñando un nuevo logo, más moderno, más esquemático, más abstracto, con líneas sencillas que querían representar la naturaleza observada desde el museo, los riscos calizos del otro margen de la hoz del Huécar: arte y naturaleza en una misma imagen, como en el museo. 
La apertura de los tres museos de arte contemporáneo ha supuesto la revitalización cultural de la zona y de la ciudad. Todos ellos han sido resultado de intervenciones de rehabilitación y cambio de uso de inmuebles infrautilizados o en desuso que ya no cumplían con las funciones para las que fueron creados: la religiosa, evidencia del papel de la Iglesia en el control del espacio urbano, sobre todo durante los siglos XVI y XVII, y la residencial. Dos edificios en la cornisa caliza de la hoz y otro en el resalte rocoso del meandro, a ambos lados del Huécar. En definitiva, tres hitos de la imagen urbana del Casco Histórico de Cuenca que con su rehabilitación han mejorado y enriquecido el paisaje urbano de la hoz del Huécar, y con la instalación de las tres colecciones de arte, la de Zóbel, Antonio Pérez y Torner, han dado lugar a lo que algunos denominan el "Triángulo del Arte" en este borde del casco, erigiéndose en motores de desarrollo al inducir un aumento del número de visitantes, nuevas necesidades, actividades y un crecimiento del número de establecimientos hosteleros y plazas en el Casco Histórico y en la ciudad en general. Y todo ello potenciado por las exposiciones temporales realizadas en el marco de la celebración del 50 aniversario del Museo de Arte Abstracto Español, lo que provocó que tan solo en un año se duplicara el número de visitantes.

Con la recuperación de edificios y su adaptación a los nuevos usos actuales no sólo se pretende recuperar el patrimonio físico o monumental de contenedores vacíos o infrautilizados que ya no prestan ningún tipo de servicio, sino también impulsar, con su reutilización, la revitalización de la Ciudad Antigua. La conservación del patrimonio residencial, el mantenimiento de la población, la construcción de nuevos edificios y la introducción de nuevas funciones como las socioculturales asociadas a estos viejos contenedores rehabilitados, están propiciando el inicio de la revitalización del Casco Histórico.

La condición de Cuenca como Ciudad Patrimonio de la Humanidad, junto con la presencia, consolidación y creación de nuevos museos, la construcción de nuevas infraestructuras de comunicación como la autovía de Castilla-La Mancha (A-40) y la línea de Alta Velocidad 5 , así como la repercusión de todo ello en el incremento de las infraestructuras de alojamiento, de plazas, de visitantes y pernoctaciones, ha generado la existencia de dinámicas y procesos territoriales que han propiciado el inicio de la regeneración de la ciudad, asociada fundamentalmente a la cultura y al sector turístico como motores de desarrollo (Aparicio, et al., 2017).

5 La estación de ferrocarril de Alta Velocidad de Cuenca se denomina Fernando Zóbel, como homenaje a quien tanto hizo por esta ciudad. 


\section{BiBLIOGRAFÍA}

Alba, E., Cortijo Talavera, A. e Iranzo García, E. (2017). Paisajes valencianos: territorio turístico. Valencia: Generalitat Valenciana, Instituto Valenciano de Tecnologías Turísticas y Universitat de València.

Almarcha Núñez Herrador, E., Díez de Baldeón García, P., Peris Sánchez, D. y Sánchez Sánchez, I. (2011). Paisajes de los Conjuntos Históricos. Castilla-La Mancha. Ciudad Real: Centro de Estudios de Castilla-La Mancha. Junta de Comunidades de Castilla-La Mancha.

Aparicio Guerrero, A.E. (1997). Urbanismo, politica territorial y reanimación económica de la provincia de Cuenca (1975-1990). Cuenca: Ediciones de la Universidad de Castilla-La Mancha.

Aparicio Guerrero, A.E. (2004). "A plena luz" y la rehabilitación del casco antiguo de Cuenca. Nimbus. Revista de Climatología, Meteorología y Paisaje, 13-14, 7186.

Aparicio Guerrero, A.E. (2013). Los centros históricos de Toledo y Cuenca. Nuevos equipamientos socioculturales para la recuperación funcional. Polígonos, 25, 19-56.

Aparicio Guerrero, A.E. y Fernández Fernández, M.C. (2004). La ciudad alta y las hoces de Cuenca: Patrimonio de la Humanidad. En II Congresso Internacional de Investigação e DesenvolvimentoSócio-cultural AGIR (18p.). Paredes de Coura; Associação para a Investigação e DesenvolvimentoSóciocultural. Centro Cultural de Paredes de Coura 28 a 30 de Outubro de 2004.

Aparicio Guerrero, A.E., Serrano Gil, O., García Marchante, J.S., y Fernández Fernández, M.C. (2017). Dinámicas y procesos territoriales: Cuenca, ciudad Patrimonio de la Humanidad. En F. Allende et al. (Ed.), Naturaleza, territorio y ciudad en un mundo global. Actas del XXV Congreso de la Asociación de Geógrafos Españoles (pp. 1498-1507). Madrid: Universidad Autónoma de Madrid.

Barrado Timón, D. (2012). Cultura y promoción urbana: el impulso autonómico. En M. Valenzuela (coord.), Proyecto URBSPAIN. El impacto del modelo autonómico en las ciudades españolas. Una aproximación interdisciplinar (pp. 595-640). Madrid: Servicio de Publicaciones de la Universidad Autónoma de Madrid.

Bolaños, M. (2006). "El futuro empieza hoy» - Los comienzos de un pequeño museo moderno. En La ciudad abstracta 1966: El nacimiento del Museo de Arte Abstracto Español (pp. 31-54). Madrid: Fundación Juan March.

Bolaños, M. (2008). Historia de los museos en España. Gijón: Ediciones Trea, 2a edición revisada y ampliada.

Bolaños, M. (2011). Orígenes del coleccionismo y gustos modernos. Amigos de los Museos, 33, 12-15. 
Bonet, J.M. (1991). Museo de Arte Abstracto Español: Cuenca. Madrid: Fundación Juan March.

Díaz Martínez, M. (2015). Restauración de arte contemporáneo y conservación preventiva. Un caso práctico: la Fundación Antonio Pérez de Cuenca. Tesis Doctoral, Universidad de Castilla-La Mancha.

Eco, U. y Pezzini, I. (2014). El museo. Madrid: Casimiro libros.

Escudero, D. y De la O, R. (2016). Apreciar, conocer y aprender desde la inmersión: El valor de la experiencia en los paisajes culturales. Amigos de los Museos. Boletín Informativo, 39, 11-14.

Fernández Fernández, M.C. (1995). El lugar y la ciudad de Cuenca. En Ciudady Mujer. Actas del Curso Urbanismo y Mujer. Nuevas visiones del espacio público y privado. Málaga, 1993, Toledo 1994. Málaga: Seminario Permanente Ciudad y Mujer.

Fernández Santos, E. (2004). Gustavo Torner vacía su estudio y entrega al Reina Sofía más de 500 obras. EL PAÍS, 3 de abril de 2004. https://elpais.com/ diario/2004/04/03/cultura/1080943209_850215.html

Fontán del Junco, M. (2018). ¿Bienvenido Mr. Zóbel? Revista de Museología, 73, 55-67.

Fontán del Junco, M. (2019). 'An Artists' Museum, a Democratic Museum. En Cuenca: City of Spanish Abstraction (pp. 17-31). Boston: McMullen Museum of Art, Boston College.

Frayle Yunta, M. (2018). Un templo consagrado al arte: El Espacio Torner. Revista de Museología, 73, 68-82.

Frías, C. (2016). Paisajes románicos en Soria. Amigos de los Museos. Boletín Informativo, 39, 26-28.

Fundación Juan March (2016). Breve historia del Museo de Arte Abstracto Español (1961-2016). En Museo de Arte Abstracto Español (pp. 175-179). Madrid.

Galisteo Espartero, A.J. (2013). Aprendiendo del Museo de Arte Abstracto Español de Cuenca. 50 años de la gestación de un modelo paradigmático. Boletín de la Sociedad de Amigos de la Cultura de Vélez-Málaga, 12, 49-54.

Galisteo Espartero, A.J. (2015). El museo de masas en España (1951-1992). Origenes y evolución de su arquitectura. Tesis Doctoral, Universidad de Málaga.

García de Paredes, A., García Pedrosa, I. y Torner, G. (2007). El Espacio Torner en la Iglesia de San Pablo (Cuenca). On Diseño, 280, 246-253.

García Marchante, J.S. (2001). El territorio de la ciudad de Cuenca. En VV. AA., La Ciudad de la Luzy del Aire (pp. 15-49). Cuenca: Ayuntamiento de Cuenca. 
García Marchante, J.S. (2003). Cuenca: la ciudad modelada por el agua y el hombre. Cuadernos de Turismo, 12, 179-190.

García Marchante, J.S. (2011). Cuenca: un destino turístico consolidado. Cuadernos de Turismo, 27, 403-418.

García Marchante, J.S. (2013). Paisajes conquenses en mi memoria. Discurso de ingreso del Ilmo. Sr. Don Joaquín Saúl García Marchante en la Real Academia Conquense de Artes y Letras, leído en Cuenca el 18 de abril de 2013 y contestación a cargo del Ilmo. Sr. Don Pedro Miguel Ibáñez Martínez en la Real Academia Conquense de Artes y Letras, Cuenca: Real Academia de Artes y Letras, 2003. Discursos Académicos, no 15.

García Marchante, J.S. y Fernández Fernández, M.C. (1999). La Ciudad Encantada. León: Lancia Ediciones.

García Martínez, J.L. (2015). Arquitectura barroca en Huete y su tierra. Tesis Doctoral, Universidad de Castilla-La Mancha.

Gómez Mendoza, J. (2003). El gobierno de la naturaleza en la ciudad. Ornato y ambientalismo en el Madrid decimonónico. Discurso leído el día 27 de abril de 2003 en el acto de su recepción por la Excma. Sra. Da Josefina Gómez Mendoza y contestado por el Excmo. Sr. D. Miguel Artola Gallego. Madrid: Real Academia de la Historia.

Ibáñez Martínez, P.M. (1997). Por tierras de Cuenca. Madrid: Ediciones Lancia. Ibáñez Martínez, P.M. (2001). Arquitectura, clima y topografía: el carmelita fray Alberto en Cuenca. Boletín del Museo e Instituto Camón Aznar, 84, 81-106.

Ibáñez Martínez, P.M. (2016a). Las Casas Colgadas y el Museo de Arte Abstracto Español. Cuenca: Consorcio Ciudad de Cuenca y Ediciones de la Universidad de Castilla-La Mancha.

Ibáñez Martínez, P.M. (2016b). Apuntes históricos sobre las Casas Colgadas. En Catálogo Museo de Arte Abstracto Español (pp. 21-37). Madrid: Fundación Juan March.

Ibáñez Martínez, P.M. (2018). La conciencia conservacionista sobre el patrimonio edificado conquense durante el primer tercio del siglo XX. En A.E. Aparicio Guerrero y R. Navarro Olivas (coord.), Imágenes humanistas para una sociedad educativa (pp. 35-57). Cuenca: Ediciones de la Universidad de Castilla-La Mancha.

ICOM (2007). Estatutos del ICOM. Disponible en http://icom.museum/ fileadmin/user_upload/pdf/Statuts/statutes_spa.pdf

ICOM (2016). Dia Internacional de los Museos 2016. El Tema. Disponible en http://network.icom.museum/international-museum-day/dim-2016/eltema/L/1/ 
Jiménez Blanco, M.D. (1993). Los museos de arte contemporáneo. En Calvo Serraller, F. (ed.), Los espectáculos del arte. Instituciones y funciones del arte contemporáneo (pp. 135-160). Barcelona: Tusquets Editores.

Jiménez Blanco, M.D. (2013). El coleccionismo de arte en España. Una aproximación desde su historia y su contexto. Barcelona: Fundación Arte y Mecenazgo

Langreo Valverde, S. (2018). El Museo de las Ciencias y el Museo de Paleontología de Castilla-La Mancha, dos centros de acción educativa. Revista de Museología, 73, 138-149.

Layuno Rosas, M.A. (2002). Los nuevos museos en España. Madrid: Edilupa Ediciones.

Lorente Lorente, J.P. (1998). Los nuevos museos de arte contemporáneo y moderno durante el franquismo. Antigrama, 13, 295-313.

Lorente, J.P. (2008). Los museos de arte contemporáneo. Noción y desarrollo histórico. Gijón: Ediciones Trea.

Lynch, K. (1984). La imagen de la ciudad. México: Gustavo Gili.

Martínez Soria, C.J. (2018). Cuenca, paradigma de arte contemporáneo. Revista de Museología, 73, 52-53.

Muñoz Bascuñana, M. (2018). Fundación Antonio Pérez. La difusión del arte contemporáneo en la provincia de Cuenca, Revista de Museología, 73, 83-97.

Nazor, O. (2016). Museos y paisajes culturales. Desafíos en clave teórica. Dia Internacional dos Museus, 18 maio. Revista Museu. Cultura levada a serio. https://www.revistamuseu.com.br/site/br/artigos/18-de-maio/18-maio2016/248-museos-y-paisajes-culturales-desafios-en-clave-teorica.html

Pol Méndez, F. y Gago, V. (1983). Una propuesta de rehabilitación: el Barrio de San Martín, en la "Ciudad Alta" de Cuenca. En VV. AA., Cuenca edificada (pp. 221-241). Madrid: Colegio Oficial de Arquitectos de Madrid.

Sagastibelza, A. (2006). Espacio Torner. Cuenca: Fundación Torner y Diputación Provincial de Cuenca.

Troitiño Vinuesa, M.A. (1984). Cuenca: evolución y crisis de una vieja ciudad castellana. Madrid: Dirección General de Acción Territorial y Urbanismo del Ministerio de Obras Públicas y Urbanismo-Universidad Complutense de Madrid.

Troitiño Vinuesa, M.A. (1992). Cascos antiguos y centros históricos: problemas, politicas y dinámicas urbanas. Madrid: Dirección General de Política Territorial y Urbanismo del Ministerio de Obras Públicas y Transportes.

Troitińo Vinuesa, M.A. (1998a). Cuenca, Patrimonio Cultural de la Humanidad: retos de futuro. En M.A. Troitińo Vinuesa y J.S. García Marchante (coord.), 
Vivir las ciudades históricas: recuperación integrada y dinámica funcional. (pp. 57-86). Cuenca: Universidad de Castilla-La Mancha

Troitińo Vinuesa, M.A. (1998b). Paisaje urbano y patrimonio cultural: el centro histórico de Cuenca. En E. Martínez de Pisón (coord.), Paisaje y Medio Ambiente (pp. 117-136). Valladolid: Universidad de Valladolid.

UNESCO (1972). Convención sobre la Protección del Patrimonio Mundial Cultural y Natural Disponible online en http://portal.unesco.org/es/ev.phpURL_ID $=13055 \&$ URL_DO=DO_TOPIC\&URL_SECTION=201.html

Vacas Guerrero, T. (2014). Los museos como agentes dinamizadores del espacio urbano. En M.L. Piñeiro Maceiras, L. Chapuis y R. Matteo (ed.), Turismo y representación espacial (pp. 147-166). Madrid: Universidad Rey Juan Carlos.

Vacas Guerrero, T. y De la Fuente, P.M. (2016). La nueva proyección del Museo de Arte Abstracto Español de Cuenca y su relación con el turismo. Estudios Turisticos, 210, 41-62.

Valenzuela Rubio, M. (1988). Cascos Históricos y dinámicas territoriales. El caso de las ciudades medias de La Meseta. En VV. AA. Toledo, ¿ciudad viva? ¿ciudad muerta? (pp. 537-551). Toledo: Universidad de Castilla-La Mancha, Colegio Universitario de Toledo, Simposio del 26 al 30 de abril de 1983.

Villalba Salvador, A. (2006). Enseñar a «ver», aprender a «ver». Fernando Zóbel antes y después de 1966. En La ciudad abstracta 1966: El nacimiento del Museo de Arte Abstracto Español (pp. 55-82). Madrid: Fundación Juan March.

Yubero Jiménez, S., Larrañaga Rubio, E. y Carrascosa, J. (2010). Turismo y museo. Estudio de público y marketing de la Fundación Antonio Pérez. En G. Ferrari et al. (coord.), Investigaciones, métodos y análisis del turismo (pp. 159-172). Oviedo: Septem Ediciones. 
